NBER WORKING PAPER SERIES

\title{
BIDDING FOR INCOMPLETE CONTRACTS: AN EMPIRICAL ANALYSIS
}

\author{
Patrick Bajari \\ Stephanie Houghton \\ Steve Tadelis \\ Working Paper 12051 \\ http://www.nber.org/papers/w12051
NATIONAL BUREAU OF ECONOMIC RESEARCH 1050 Massachusetts Avenue
Cambridge, MA 02138
February 2006

We thank Jon Levin, Phil Haile, Igal Hendel and especially Han Hong for helpful discussions. We are grateful for financial support from the National Science Foundation. The views expressed herein are those of the author(s) and do not necessarily reflect the views of the National Bureau of Economic Research.

(C2006 by Patrick Bajari, Stephanie Houghton, and Steve Tadelis. All rights reserved. Short sections of text, not to exceed two paragraphs, may be quoted without explicit permission provided that full credit, including (C) notice, is given to the source. 
Bidding for Incomplete Contracts: An Empirical Analysis

Patrick Bajari, Stephanie Houghton, and Steve Tadelis

NBER Working Paper No. 12051

February 2006

JEL No. D23, D82, H57, L14, L22

\begin{abstract}
Procurement contracts are often incomplete because the initial plans and specifications are changed and refined after the contract is awarded to the lowest bidder. This results in a final cost to the buyer that differs from the low bid, and may also involve significant adaptation and renegotiation costs. We propose a stylized model of bidding for incomplete contracts and apply it to data from highway paving contracts. Reduced form regressions suggest that bidders respond strategically to contractual incompleteness and that adaptation costs, broadly defined, are an important determinant of the observed bids. We then estimate the costs of adaptation and bidder markups using a structural auction model. The estimates suggest that adaptation costs on average account for about ten percent of the winning bid. The distortions from private information and local market power, which are the focus on much of the literature on optimal procurement mechanisms, are much smaller by comparison.

Patrick Bajari

Department of Economics

University of Michigan

266 Lorch Hall

611 Tappan Street

Ann Arbor, MI 48109-1220

and NBER

bajari@umich.edu

Stephanie Houghton

Duke University

stephanie.houghton@duke.edu

Steve Tadelis

University of California, Berkeley

stadelis@haas.berkeley.edu
\end{abstract}




\section{Introduction}

Procurement of goods and services is commonly performed using auctions of one type or another, the benefits of which are well known and vigorously advocated. Namely, competitive bidding will result in low prices and sets rules that limit the influence of favoritism and political ties. When the good being procured is complex and hard to specify, it is often the case that alterations to the original design are needed after the contract is awarded and production begins. This may result in considerable discrepancies between the lowest winning bid and the actual costs that are incurred by the buyer.

A leading example is the massive highway artery in Boston, referred to as the "Big Dig" by locals. On this project, 12,000 changes to more than 150 design and construction contracts have led to \$1.6 billion in cost overruns, many of which can be traced back to unsatisfactory design and site conditions that differed from expectations. For example, the original designs were made with maps that did not include the Fleet Center Arena and instead showed an obstacle-free area for the general contractor Bechtel to install utility lines. $^{2}$

As in the Big Dig, many construction projects involve a modification of the initial plans and specifications. These typically result in a cost increase that follows from two sources. The first are the direct costs of the additional work, which we refer to as production costs. The second, which we refer to as adaptation costs, are any costs that are incurred above and beyond the direct production costs of the project. For example, changing the contract disrupts the normal flow of work and thus increases the effort needed to coordinate workers, subcontractors and material suppliers, effort that could have been avoided with adequate planning in advance. Also, renegotiating the contract generates adaptation costs in the form of haggling, dispute resolution and opportunistic behavior. That said, in both the theoretical and empirical auctions literature, the issue of contractual incompleteness is ignored almost without exception. This paper makes a first attempt to measure the magnitude of adaptation costs and to quantify their importance in determining observed bidding behavior.

Our analysis begins by observing that highway improvement projects are often procured using unit-

2 According to the Boston Globe, “About \$1.1 billion of that can be traced back to deficiencies in the designs, records show: $\$ 357$ million because contractors found different conditions than appeared on the designs, and \$737 million for labor and materials costs associated with incomplete designs.” Responsibility for these cost overruns is a subject of heated debate. See

http://www.boston.com/news/specials/bechtel/part_1/. 
price auctions. These are tailored to situations where there is little uncertainty about the measurable inputs needed for production, but there may be significant uncertainty about the actual quantities of each input that will ultimately be needed. Procurement starts with an engineer's estimate of the quantities of each work item that will be used. Contractors then bid a per unit price for each item, and the contractor with the lowest estimated total bid, computed by multiplying the unit prices by the estimated quantities, is the winner.

The total estimated bid is seldom equal to the final price paid by the buyer. This is because the ex ante estimated quantities and the ex post actual quantities never perfectly agree. There may also be changes in scope, where the overall aims of the project need to be altered. Changes in scope may be necessary, as in accounting for the Fleet Center in Boston's Big Dig, when the original plans and specifications prove severely flawed. The monetary value of these alterations can be significant. In our data, for example, the final payment was, on average, $4.8 \%$ higher than the winning bid, and sometimes was in excess of $50 \%$ more.

We have collected a unique panel data set of bids on highway contracts from the California Department of Transportation (Caltrans). The data includes bidder identities, unit prices, cost estimates for each work item, and measures of market power such as a bidder's distance to the project and backlog. The data also contains detailed information on how the initial designs were altered, which is not available in most studies of procurement. For all work items in the contract, the data set includes actual quantities installed and payments to the contractor from changes in scope. The data is remarkably detailed compared to what is normally available in Empirical Industrial Organization.

For instance, we can construct an engineer's estimate for installing the actual quantities, whereas in Empirical I.O. cost information is usually quite incomplete - if it exists at all. This allows us to construct estimates of the direct production costs, which in turn allow us to use the final payments data to construct measures of adaptation costs that differ from direct production costs.

To do this we estimate a structural model that measures three potential sources of inefficiency. First, we estimate bidders' markups as a function of private information and local market power. Second, we quantify the importance of incentives to submit “unbalanced” bids. As in Athey and Levin (2001), contractors can increase expected profits by shading up unit prices on items that are expected to overrun and decreasing unit prices on items that are expected to underrun. Finally, we estimate the adaptation costs from changing the initial designs. To control for omitted variables that might bias our estimates of adaptation costs, we propose an instrumental variables strategy that exploits exogenous variation in how the contract is adapted.

This paper is related to a recent literature on procurement when the original contract is subject to ex post changes. Several studies emphasize the importance of adaptation costs, including Williamson (1975, 1985), Corts and Singh (2004), Chakravarty and MacLeod (2004) Crocker and Reynolds (1993), Bajari and Tadelis (2001), and Bajari, McMillan and Tadelis (2004). ${ }^{3}$ Our paper is also related to a growing literature

\footnotetext{
3 Problems resulting from changing construction contracts have also been discussed in an academic literature in construction
} 
on structural estimation of auction models. See for instance, Paarsch (1992), Donald and Paarsch (1993), Guerre, Perrigne and Vuong (2000), Campo et al. (2002), Pesendorfer and Jofre-Bonet (2003), and Athey, Levin and Seira (2004). ${ }^{4}$

This paper makes three contributions to the literature. First, our results suggest that standard models of bidding are often misspecified because they do not account for the significant discrepancies between initial bids and the final payments. Payments from changes to the contract can be substantial, implying that an important part of a contractor's revenue is omitted in standard theoretical and empirical models.

Second, we simultaneously estimate distortions from market power, incentives to submit unbalanced bids and adaptation costs in an auction model. The estimates imply that adaptation costs are significanton average they are equal to about ten percent of the winning bid. Market power and unbalanced bidding, on the other hand, appear to be a fairly modest component of the markup. This finding is consistent with our reading of the literature on construction and engineering management that we surveyed in Bajari and Tadelis (2001).

Third, our paper contributes to transaction costs economics by actually estimating adaptation costs. While transaction cost economics dates back to the original arguments laid out by Williamson $(1975,1985)$, to the best of our knowledge, there are no empirical estimates of the dollar value of some of these costs. As Pakes (2003) argues, one of the uses of structural estimation is to recover estimates of costs that are not directly observed in the data. We demonstrate that standard methods for estimating auctions can be modified to yield an estimate of adaptation costs.

\section{Competitive Bidding for Highway Contracts}

As described in Hinze (1993) and Clough and Sears (1994), procurements for highway construction, as well as many other procurements in the public sector, are often done through competitive bidding for unitprice contracts. For such contracts, civil engineers first prepare a list of items that describe the tasks and materials required for the job. For example, in the contracts we investigate, items include laying asphalt, installing new sidewalks and striping the highway. For each work item, the engineers provide an estimate of the quantity that they anticipate contractors will need in order to complete the job. For example, they might estimate 25,000 tons of asphalt, 10,000 square yards of sidewalk and 50 rumble strips. The itemized list is publicly advertised along with a detailed set of plans and specifications that describe how the project is to be completed.

A contractor that wishes to bid on the project will propose per unit prices for each of the work items on the engineer's list. A contractor's bid is therefore a vector of unit prices that specifies his price for each

and engineering management. See Bartholomew (1998), Clough and Sears (1994), Ibbs et. al. (1986) and Sweet (1994).

4 Other researchers that have studied bidding for highway contracts include Porter and Zona (1993), Hong and Shum (2002), Krasnokutskaya (2004), Bajari and Ye (2003), Pesendorfer and Jofre-Bonet (2003) and Krasnokutskaya and Seim (2004). 
contract item. Table 1 shows the basic structure of a completed bid, which must be sealed and submitted prior to a set bid date. When the bids are opened, the contract is awarded to the contractor with the lowest estimated total bid, defined as the sum of the estimated individual line item bids (calculated by multiplying the estimated quantities of each item by the unit prices in the bid). ${ }^{5}$

\begin{tabular}{|l|l|r|r|r|}
\hline Item & Description & Estimated Quantity & Per Unit Bid & Estimated Item Bid \\
\hline 1. & asphalt (tons) & 25,000 & $\$ 25.00$ & $\$ 625,000.00$ \\
\hline 2. & sidewalk (square yds) & 10,000 & $\$ 9.00$ & $\$ 90,000.00$ \\
\hline 3. & rumble strips & 50 & $\$ 5.00$ & $\$ 250.00$ \\
\hline & \multicolumn{3}{|c}{ Final Bid: } & $\$ 715,250.00$ \\
\hline
\end{tabular}

Figure 1: Unit Price Contract-An Example.

As a rule of thumb, final quantities are never equal to the estimated quantities. For example, the engineers might estimate that it will take 25,000 tons of asphalt to resurface the stretch of highway listed in the plans but 26,752 tons are actually used. The difference, in fact, may be substantial if there are unexpected conditions or work has to be redone or eliminated. As a result, final payments made to the contractor are almost never equal to the original bid. The determination of the final payment can be rather complicated, and in many cases is not the simple sum of actual item costs given the unit prices in the bid. Caltrans' Standard Specifications and its Construction Manual discuss the determination of the final payment at length. To a first approximation, there are three primary reasons for modifying the payments away from the simple vector product of unit prices and actual quantities.

First, if the difference between the estimated and actual quantities is small, then the contractor will indeed be paid the unit price times the actual quantity used. If the deviation is larger, however, or if it is thought to be due to negligence by one party, both sides will renegotiate an adjustment of compensation. ${ }^{6}$ This adjustment is the difference between the vector product of the unit prices and actual quantities and the amount that the contractor is actually paid for the contract items. Consider the contract in Figure 1. If the asphalt ran over by 10,000 tons, instead of just a few thousand, Caltrans would hesitate to pay $\$ 250,000$ more than they had anticipated. The parties might negotiate an adjustment of $-\$ 20,000$ to bring the total bill down. In our data, these adjustments are always recorded as a lump sum reduction or increase, but one might also think of them as a way for parties to adjust the implied unit price on a particular item.

Second, in addition to changes in the estimated quantities, there may be a change in scope of the project. A change in scope is a change in the overall description and design of the project that needs to be completed.

5 There are situations in which the Department of Transportation (DOT) can choose not to award the contract to the low bidder. The low bid can be rejected if the bidder is not appropriately bonded or does not have a sufficient amount of work awarded to disadvantaged business enterprises as subcontractors. Also, the DOT may reject bids judged to be highly unbalanced and therefore irregular.

6 In the particular case of highway construstion procured by Caltrans, this type of adjustment is called for if the actual quantity of an item varies from the engineer's estimate by 25 percent or more. See the discussion of changes in the Standard Specifications and the Construction Manual. 
For instance, the original scope of the project might be to resurface 2 miles of highway. However, the engineers and contractor might discover that the subsurface is not stable and that certain sections need to be excavated and have gravel added. This would constitute a change in scope. In most cases, the contractor and Caltrans will negotiate a change order that amends the scope of the contract as well as the final payment. If negotiations break down, this may lead to arbitration or a lawsuit. Payments from changes in scope will appear in two ways. First, to the extent that the change in scope affects prespecified contract items, changes in the actual ex post quantities of those items will compensate the contractor for the direct production costs. Second, extra payments may reflect the use of unanticipated materials or other adjustment costs, and they are recorded as extra work in our data.

Finally, the payment may be altered because of deductions imposed by Caltrans. If work is not completed on time or if it fails to meet standard specifications, Caltrans may deduct liquidated damages. Such deductions may be a source of disputes between Caltrans and the contractor. The contractor may argue that the source of the delay is poor planning or inadequate specifications provided by Caltrans, while Caltrans might argue that the contractor's negligence is the source of the problem. The final deductions imposed may be the outcome of heated negotiations or even lawsuits and arbitrations between contractors and Caltrans.

It is widely believed in the industry that some contractors attempt to strategically manipulate their bids in anticipation of changes to the payment. Contractors may strategically read the plans and specifications to forecast the likelihood and magnitude of changes to the contract. For instance, consider the example of Figure 1, in which the total bid is $\$ 715,250$. Suppose that after reading the plans and specifications, the contractor expects asphalt to overrun by 5,000 tons and sidewalk to underrun by 3,000 square feet. If he changes his bid on sidewalk to $\$ 5.00$ and his bid on asphalt to $\$ 26.60$ then his total bid will be unchanged. However, this will increase the contractors' expected total payment to $\$ 833,750.00(26.6 \times 30,000+5 \times$ $7000+5 \times 50$ ) compared to $\$ 813,750.00$ when bids of $\$ 25.00$ and $\$ 9.00$ are entered. A profit maximizing contractor can therefore increase his total payment without increasing his total bid and thus will not lower his probability of winning the job. A bid is referred to as unbalanced if it has unusually large unit prices on items that are expected to overrun and unusually small unit prices on items expected to underrun.

Athey and Levin (2001) note that the optimal strategy for a risk neutral contractor is to submit a bid that has zero unit prices for some items that are overestimated, and put all the actual costs on items that are underestimated. This strategy will maximize the expected ex post payment while keeping the total bid unaltered. In the data, however, while zero unit price bids have been observed, they are very uncommon. Athey and Levin argue that risk aversion is one reason why this might occur, which in the absence of ex post changes seems like a plausible explanation for bidding behavior. After speaking with some highway contractors and reading industry sources we believe that for construction contracts other incentives are more important. Namely, Caltrans is not required to accept the low bid if it is deemed to be irregular (see Sweet (1994) for an in depth discussion of irregular bids). A highly unbalanced bid is a sufficient condition for a 
bid to be deemed irregular. As a result, a bid with a zero unit price is very likely, if not certain to be rejected. In our data, 4 percent of the contracts are not awarded to the low bidder, and according to industry sources the mostly likely reason is unbalanced bids. ${ }^{7}$

Also, the Standard Specifications and the Construction Manual indicate that unit prices on items that overrun by more than 25 percent are open to renegotiation. In these negotiations, Caltrans engineers will attempt to estimate a fair market value for a particular unit price based on bids submitted in previous auctions and other data sources. Caltrans may also insist on renegotiating unit prices even when the overrun is less than 25 percent if the unit prices differ markedly from estimates. This suggests that there are additional limitations on the benefits of submitting a highly unbalanced bid.

\section{Bidding for Incompletely Specified Contracts}

In this section we use the factual descriptions above to develop a simple variant of a standard private values auction model that will be the basis for our reduced form and structural empirical models.

\subsection{Basic Setup}

A project is characterized by a list of tasks, $t=1, \ldots, T$ and a vector of estimated quantities that are proposed by the buyer and distributed to the potential contractors. The estimated quantity for each task is $q_{t}^{e}$, while the actual ex post quantity that will be needed to complete the task is $q_{t}^{a}$. We will let $\mathbf{q}^{e}=\left(q_{1}^{e}, \ldots, q_{T}^{e}\right)$ and $\mathbf{q}^{a}=\left(q_{1}^{a}, \ldots, q_{T}^{a}\right)$ denote the vectors of estimated and actual quantities.

Since the focus of our study is on the potential adaptation costs from ex post changes and not on the rents that contractors receive due to their private information, we assume an extreme form of asymmetric information between the buyer and contractors. In particular, we assume that each contractor in the set of available bidders has perfect foresight about the actual quantities $\mathbf{q}^{a}$ while the buyer Caltrans is unaware of $\mathbf{q}^{a}$ and only considers $\mathbf{q}^{e}$. The perfect foresight of contractors can naively be interpreted as the contractors knowing the actual $\mathbf{q}^{a}$. Since we will assume that contractors are risk neutral, this specification can more convincingly be interpreted as contractors not having exact information about $\mathbf{q}^{a}$, but instead having symmetric uncertainty about the actual quantities, resulting in common expectations over actual quantities. This interpretation is useful for the empirical analysis because it generates a source of noise that is not specific to the contractor's information or the observable project characteristics.

Despite the fact that contractors have symmetric information about $\mathbf{q}^{a}$, they differ in their private information about their own costs of production. Let $c_{t}^{i}$ denote firm $i$ 's per unit cost to complete task $t$ and let $\mathbf{c}^{i}=\left(c_{1}^{i}, \ldots, c_{T}^{i}\right) \in \Re_{+}^{T}$ denote the vector of $i$ 's unit costs. The total cost to $i$ for installing the vector of quantities $\mathbf{q}^{a}$ will be $\mathbf{c}^{i} \cdot \mathbf{q}^{a}$, the vector product of the costs and the actual quantities. The costs (type) of

7 Using blue book prices and previous bids, CalTrans is able to check whether bids for certain work items are unusually high or low. 
contractor $i$ are drawn from a well behaved joint density $f_{i}\left(\mathbf{c}^{i}\right)$ with support on a compact subset of $\Re_{+}^{T}$. The distributions are common knowledge, but only contractor $i$ knows $\mathbf{c}^{i}$. Also costs are independently distributed conditional on publicly observed information. We note that the private values assumption is commonly used when studying this industry (see Porter and Zona (1993), Krasnokutskaya (2004), Bajari and Ye (2003), and Pesendorfer and Jofre-Bonet (2003)). Testing for common values in this model with multiple units is much more complicated than in a single unit auction, and is beyond the scope of this research.

This specification, together with the symmetric information that contractors have about $\mathbf{q}^{a}$, depicts a situation where contractors have rational expectations about what needs to be done to meet the contract (as in the most common type of procurement models) but they have private information about the costs of production.

Contractors bid by submitting a unit price vector $\mathbf{b}^{i}=\left(b_{1}^{i}, \ldots, b_{T}^{i}\right)$ where $b_{t}^{i}$ is the unit price bid by contractor $i$ on item $t$. Contractor $i$ wins the auction and is awarded the contract if and only if $\mathbf{b}^{i} \cdot \mathbf{q}^{e}<\mathbf{b}^{j} \cdot \mathbf{q}^{e}$ for all $j \neq i$. That is, the contract is awarded to the lowest bidder, where the total bid is defined as the vector product of the contractor's unit price bids and the estimated quantities. This implies that our bidders participate in an auction with a simple linear scoring rule where each bid vector is transformed into a unidimensional score, the estimated price. ${ }^{8}$

Let $R\left(\mathbf{b}^{i}\right)$ be the gross revenue that a contractor expects to receive when he wins with a bid of $\mathbf{b}^{i}$. If a risk neutral contractor has costs $\mathbf{c}^{i}$ then his expected profit from submitting a bid $\mathbf{b}^{i}$ is given by,

$$
\pi_{i}\left(\mathbf{b}^{i}, \mathbf{c}^{i}\right)=\left(R\left(\mathbf{b}^{i}\right)-\sum_{t=1}^{T} c_{t}^{i} q_{t}^{a}\right)\left(\operatorname{Pr}\left\{\sum_{t=1}^{T} b_{t}^{i} q_{t}^{e}<\sum_{t=1}^{T} b_{t}^{j} q_{t}^{e} \text { for all } j \neq i\right\}\right)
$$

where the interpretation is standard: the contractor receives the net payoff of revenue less production costs only in the event that all other bidders submit higher bids as calculated using the expected actual quantities.

\subsection{Revenues and adaptation costs}

If the only source of revenue were the vector product of the unit prices with the actual quantities, then revenues would equal $\sum_{t=1}^{T} b_{t}^{i} q_{t}^{a}$. As discussed in the previous section, however, there are three other components that affect the gross revenue of the project: adjustments, extra work, and deductions. Following our assumption of risk neutrality, and assuming that the contractors have symmetric rational expectations about the distribution of each component, we can introduce each of these three components as expected values, and include them additively into the contractors' profit function. ${ }^{9}$ We denote the expected income

\footnotetext{
8 See Osband and Reichelstein (1985), Che (1993), and Bushnell and Oren (1994) for early work on scoring auctions, and a recent generalization by Asker and Cantillon (2004).

9 As mentioned earlier, another simplistic way of interpreting this is that contractors have perfect foresight of these components. An alternative assumption would be that each contractor receives a signal of this common value, which would complicate the model beyond tractability.
} 
(or loss) from adjustments as $A$, from extra work as $X$, and from deductions as $D$.

In the absence of adaptation costs, given actual quantities $\mathbf{q}^{a}$ the profits to the winning bidder $i$ would be

$$
\sum_{t=1}^{T}\left(b_{t}^{i}-c_{t}^{i}\right) q_{t}^{a}+A+X+D
$$

If this were indeed the case, then any payments captured by $A+X+D$ are just a transfer of funds from the buyer to the contractor. However, in the presence of adaptation costs every dollar that is transferred through this channel has less than its full impact on profits.

A first source of adaptation costs are the resources devoted to contract renegotiation and dispute resolution. Estimates place the value of change orders at \$13 to \$26 billion per year, but researchers have noted that with the additional costs related to filing claims and legal disputes, the total cost of changes could reach $\$ 50$ billion annually (see Hanna and Gunduz (2004)). When a change is required, Caltrans may argue that failure to follow the original designs generated the need for change, while the contractor may argue that inadequate designs provided by Caltrans are to blame. The parties might therefore disagree about the compensation the contractor should receive from the change order. Moreover, they may similarly disagree over the best way to change the plans and specifications. The contractor might prefer an alteration that maximizes his profits from the change order, while Caltrans may desire an alternative alteration that minimizes the total cost. Disputes over changes may generate a breakdown in cooperation on the project site and possibly lawsuits.

A second source of adaptation costs are the additional costs of adapting to new site conditions and unanticipated work. Large highway repair projects require careful coordination between the general contractor, his workers, subcontractors, material suppliers and Caltrans engineers. Changes can disrupt the efficient rhythm of work on the job. It is not unusual for changes to cut in half the amount of asphalt laid by a contractor in a day. At this reduced rate, the project will take twice as long to complete and perhaps double costs. $^{10}$

We choose to be agnostic about the exact source of adaptation costs, which in reality are likely to be generated by a combination of several sources of bargaining frictions and costs from disrupting the normal

10 An example witnessed by one of the authors who worked on highway construction as a college student occurred while overlaying a concrete highway with asphalt. The concrete highway was approximately 30 years old and had innumerable cracks that had been patched with a dark, black "latex joint sealer". As paving began, the latex joint sealer came in contact with hot asphalt, which is typically 275 degrees. The now heated joint sealer would often (and sometimes dramatically!) explode through the freshly laid mat of asphalt. As a result, the latex joint sealer had to be removed from thousands of cracks by laborers using mostly hand tools before state engineers would allow the contractor to overlay the existing concrete road. This greatly slowed down the rate at which paving could occur, causing trucks to frequently stand in line for an hour before they could dump their asphalt into the paver. Not surprisingly, project costs skyrocketed. The contractor and the state engineers disagreed about the optimal method to deal with the latex crack sealer. The contractor preferred a method that would use less manpower and more machines to remove the crack sealer. Since the machines removed the crack sealer incompletely, the state preferred a method that had labors remove the sealer by hand. The contractor and the state engineers disagreed vehemently about the additional expense caused by the need to remove the crack sealer. Compensation for this change had to be renegotiated at length. 
flow of work. Instead, we inject a reduced form of adaptation costs into the standard model described above. We do this by introducing coefficients that will be a measure of the dissipated surplus and other adaptation costs for each of the three revenue components related to changes.

First, it is useful to distinguish between positive and negative ex post adjustments to revenues. By definition, any extra work adds compensation to the contractor while any deduction is an ex post loss incurred by the contractor. ${ }^{11}$ This implies that $X>0$ and $D<0$. The adjustments $A$, however, can be positive or negative. For this reason we separate them so that positive adjustments are labeled $A_{+}>0$ while negative ones are labeled $A_{-}<0$. We can write down the total ex post revenue as,

$$
\sum_{t=1}^{T} b_{t}^{i} q_{t}^{a}+\left(1-\beta_{+}\right) A_{+}+\left(1+\beta_{-}\right) A_{-}+(1-\gamma) X+(1+\delta) D .
$$

To interpret (1) first note that for positive ex post income, adaptation costs will cause some fraction of the surplus to be dissipated. Therefore, the positive coefficients $\beta_{+}$and $\gamma$ are a measure of these losses. For negative ex post income, adaptation costs mean that the contractor will suffer a loss above and beyond the accounting contractual loss imposed by the adjustments or deductions. Therefore, the positive coefficients $\beta_{-}$and $\delta$ are a measure of these losses.

If there are no adaptation costs involved, then all four coefficients would be equal to zero. Thus, these coefficients capture a particular linear reduced form of the adaptation costs imposed by ex post changes. This specification may be incorrect if, say, adaptation costs are not linear. Indeed, if one thinks about the stories of haggling and influence cost inefficiencies, then it is likely that as the stakes are higher, so will be the wasteful effort, maybe resulting in non-linear adaptation costs. As a first step, however, this simple specification is useful in that the lack of adaptation costs will be revealed by the data if the estimated coefficients are zero. If they are not, however, then this will indicate the presence of adaptation costs, the exact form of which can then be measured with more scrutiny.

To complete the specification of profits, we add a component that captures the loss from submitting irregular bids that are highly skewed. Athey and Levin (2001) argue that risk aversion may be one reason to avoid skewed bids. After speaking with some highway contractors and reading industry sources such as Bartholomew (1998), Clough and Sears (1994), Hinze (1993) and Sweet (1994), we believe that other incentives may be more important to curtail skewed bidding, and we discussed these in the previous section (e.g. the fact that Caltrans is highly likely to reject unbalanced bids).

We impose a reduced form penalty that is increasing in the skewness of the bid. Clearly, the degree of skewness will depend on what "reasonable prices" would be. In practice, Caltrans engineers collect information from past bids and market prices to create an estimate $\bar{b}_{t}$ that represents the engineer's estimate

11 Forced deductions are clearly a penalty. We are thus implicitly assuming that when changes in scope are agreed upon then the voluntary acceptance by the contractor implies that he is not losing money, by revealed preference. 
for the unit cost of contract item $t$. Thus, given a vector of prices $\mathbf{b}^{i}$, a natural measure of skewness would be the distance from the engineer's estimate $\overline{\mathbf{b}}$.

Let $P\left(\mathbf{b}^{i} \mid \overline{\mathbf{b}}\right)$ denote the continuously differentiable penalty function of skewing bids. We impose four assumptions on $P\left(\mathbf{b}^{i} \mid \overline{\mathbf{b}}\right)$. First, $P(\overline{\mathbf{b}} \mid \overline{\mathbf{b}})=0$, that is, there is no penalty from submitting a bid that matches the engineer's estimates. Second, $\left.\frac{\partial P\left(\mathbf{b}^{i} \mid \overline{\mathbf{b}}\right)}{\partial b_{t}^{i}}\right|_{b_{t}^{i}=\bar{b}_{t}}=0$, which implies that when the bids match the engineer's estimates, the first order costs of skewing are zero. These two assumptions seem natural ways to capture the costs of skewed bidding given the practices of Caltrans. Third, we assume that $P\left(\mathbf{b}^{i} \mid \overline{\mathbf{b}}\right)$ is strictly convex, and finally, we assume that $\left.\frac{\partial P\left(\mathbf{b}^{i} \mid \overline{\mathbf{b}}\right)}{\partial b_{t}^{i}}\right|_{b_{t}^{i}=0}$ is very negative. These last two assumptions guarantee an interior solution to the bidders' optimization problem in the choice of $\mathbf{b}^{i}$.

In our empirical specification we impose the following convenient functional form, ${ }^{12}$

$$
P\left(\mathbf{b}^{i} \mid \overline{\mathbf{b}}\right)=\alpha \sum_{t=1}^{T}\left(b_{t}^{i}-\bar{b}_{t}\right)^{2}\left|\frac{q_{t}^{e}-q_{t}^{a}}{q_{t}^{e}}\right| .
$$

While in principal we could consider a more flexible penalty function for unbalancing, the number of observations will limit the number of parameters we can include in this term. This, together with our objective of keeping the structure of the model as close to the standard literature as possible, is why we introduce this fairly parsimonious specification. This completes the specification of revenues as,

$$
R\left(\mathbf{b}^{i}\right)=\sum_{t=1}^{T} b_{t}^{i} q_{t}^{a}+\left(1-\beta_{+}\right) A_{+}+\left(1+\beta_{-}\right) A_{-}+(1-\gamma) X+(1+\delta) D-P\left(\mathbf{b}^{i} \mid \overline{\mathbf{b}}\right)
$$

\subsection{Equilibrium Bidding Behavior}

Following standard auction theory, we will consider the Bayesian Nash Equilibrium of the static first-price sealed-bid auction as our solution concept. Our model is an independent private values setting that is similar to the multidimensional-type models of Che (1993) and is in many ways a simple special case of Asker and Cantillon (2004) where the project is fixed, and the principal's (buyer's) objective is trivially fixed given that the scoring rule is fixed. Similar to Che's "productive potential” and Asker and Cantillon's "pseudotype," our equilibrium behavior will be determined as if our bidders have a unidimensional type. The reason is that given the scoring rule, the choice of total bid, or score $s=\mathbf{b}^{i} \cdot \mathbf{q}^{e}$ is separable from the optimal choice of the actual bid vector $\mathbf{b}^{i}{ }^{13}$ As a result, the Bayesian game will have a unique pure strategy monotonic equilibrium.

12 Strictly speaking, this does not guarantee that $\left.\frac{\partial P\left(\mathbf{b}^{i} \mid \overline{\mathbf{b}}\right)}{\partial b_{t}^{i}}\right|_{b_{t}^{i}=0}$ is very large, but we continue to assume that an interior solution exists. The estimates of the data will act as a reasonable reality check.

13 That is, given the costs $\mathbf{c}^{i}$, and given a promised score (price) $s$, each bidder has an optimal choice of bids conditional on winning, $b_{t}^{i}\left(\mathbf{c}^{i}\right)$, and given this optimal price policy, there is an optimal score $s\left(\mathbf{c}^{i}\right)$ that is unidimensional. This is like Asker and Cantillon's pseudotype. 
The probability that bidder $i$ wins the auction with bid $\mathbf{b}^{i}$ depends on the distribution of the bids of each of the other $j \neq i$ contractors. Let $H_{j}(\cdot)$ be the cumulative distribution function of contractor $j$ 's total bid, $\mathbf{b}^{j} \cdot \mathbf{q}^{e}$. The probability that contractor $i$ with a total bid of $\mathbf{b}^{i} \cdot \mathbf{q}^{e}$ bids more than contractor $j$ is $H_{j}\left(\mathbf{b}^{i} \cdot \mathbf{q}^{e}\right)$. Thus, the probability that $i$ wins the job with a total bid of $\mathbf{b}^{i} \cdot \mathbf{q}^{e}$ is $\prod_{j \neq i}\left(1-H_{j}\left(\mathbf{b}^{i} \cdot \mathbf{q}^{e}\right)\right)$. Using this, as well as substituting for revenues with (2), yields the contractor's profit function,

$$
\pi_{i}\left(\mathbf{b}^{i}, \mathbf{c}^{i}\right)=\left(R\left(\mathbf{b}^{i}\right)-\mathbf{c}^{i} \cdot \mathbf{q}^{a}\right) \times \prod_{j \neq i}\left(1-H_{j}\left(\mathbf{b}^{i} \cdot \mathbf{q}^{e}\right)\right)
$$

Given the cost vector $\mathbf{c}^{i}$, the contractor chooses unit prices to maximize expected utility. Substituting (2) for $R\left(\mathbf{b}^{i}\right)$, the partial derivative of profit with respect to the unit price $b_{t}^{i}$ is:

$$
\begin{aligned}
\frac{\partial \pi_{i}}{\partial b_{t}^{i}}= & \left(q_{t}^{a}-2 \alpha\left(b_{t}^{i}-\bar{b}_{t}\right)\left|\frac{q_{t}^{e}-q_{t}^{a}}{q_{t}^{e}}\right|\right) \prod_{j \neq i}\left(1-H_{j}\left(\mathbf{b}^{i} \cdot \mathbf{q}^{e}\right)\right) \\
& +\left(\sum_{t}\left(b_{t}^{i}-c_{t}^{i}\right) q_{t}^{a}-\alpha \sum_{t}\left(b_{t}^{i}-\bar{b}_{t}\right)^{2}\left|\frac{q_{t}^{e}-q_{t}^{a}}{q_{t}^{e}}\right|+\left(1-\beta_{+}\right) A_{+}+\left(1+\beta_{-}\right) A_{-}+(1-\gamma) X+(1+\delta) D\right) \\
& \times\left(-\sum_{k \neq i} \frac{\partial H_{k}}{\partial b} q_{t}^{e} \prod_{j \neq i, k}\left(1-H_{j}\left(\mathbf{b}^{i} \cdot \mathbf{q}^{e}\right)\right)\right)
\end{aligned}
$$

From our assumptions on the densities of types and on the penalty function, $H_{j}(\cdot)$ is differentiable with density $h_{j}(\cdot)$, and the first order conditions are necessary and sufficient for describing optimal bidder behavior. Thus, if at the optimum $\frac{\partial \pi_{i}}{\partial b_{t}^{i}}=0$ for all $t$, then we get $t$ equations from the fact that for all $t \in\{1, \ldots, T\}$,

$$
\begin{aligned}
\left(\mathbf{b}^{i}-\mathbf{c}^{i}\right) \cdot \mathbf{q}^{a}= & \frac{1}{q_{t}^{e}}\left(q_{t}^{a}-2 \alpha\left(b_{t}^{i}-\bar{b}_{t}\right)\left|\frac{q_{t}^{e}-q_{t}^{a}}{q_{t}^{e}}\right|\right)\left(\sum_{j \neq i} \frac{h_{j}\left(\mathbf{b}^{i} \cdot \mathbf{q}^{e}\right)}{1-H_{j}\left(\mathbf{b}^{i} \cdot \mathbf{q}^{e}\right)}\right)^{-1} \\
& +\alpha \sum_{t}\left(b_{t}^{i}-\bar{b}_{t}\right)^{2}\left|\frac{q_{t}^{e}-q_{t}^{a}}{q_{t}^{e}}\right|-\left(1-\beta_{+}\right) A_{+}-\left(1+\beta_{-}\right) A_{-}-(1-\gamma) X-(1+\delta) D
\end{aligned}
$$

A Bayesian Nash Equilibrium is a collection of bid functions, $\mathbf{b}^{i}: \Re^{T+4} \rightarrow \Re^{T}$, that maps costs and expectations over changes to unit price bids, and simultaneously satisfies the system (3) for all bidders $i \in N$. As stated above, there is a unique monotonic equilibrium in pure strategies, and we will therefore use (3) as the basis for our empirical analysis.

The first order condition (3) provides some insight into a firm's optimal bidding strategy, and relates to the established literature of bidding without adaptation costs and changes. When $\mathbf{q}^{e}=\mathbf{q}^{a}$ and when there are no anticipated changes, the first order condition reduces to: 


$$
\mathbf{b}^{i} \cdot \mathbf{q}^{e}-\mathbf{c}^{i} \cdot \mathbf{q}^{e}=\left(\sum_{j \neq i} \frac{h_{j}\left(\mathbf{b}^{i} \cdot \mathbf{q}^{e}\right)}{1-H_{j}\left(\mathbf{b}^{i} \cdot \mathbf{q}^{e}\right)}\right)^{-1}
$$

This is the first order condition to the standard first price, asymmetric auction model with private values. Thus, it is easy to see that our model is a simple variant of the standard models of bidding for procurement contracts (e.g., Porter and Zona (1993), Hong and Shum (2002), Pesendorfer and Jofre-Bonet (2003), Bajari and Ye (2003), Campo (2004), Krasnokutskaya (2004) and Krasnokutskaya and Seim (2004)). That is, the markups should reflect the contractors' cost advantage and informational rents as captured in the right hand side of (4).

For example, in our application markups should depend on whether or not contractor $i$ 's competitors are close or far from the project site, since this determines his relative advantage or disadvantage in the costs of hauling equipment and material. The markups should also depend on contractor $i$ 's uncertainty about his competitors' costs. Intuitively, we expect informational rents to increase as uncertainty about one's competitors' costs grows.

The innovation of the first order condition in (3) is the introduction of empirically measurable terms that are commonly ignored in previous studies. The first term, $\alpha \sum_{t}\left(b_{t}^{i}-\bar{b}_{t}\right)^{2}\left|\frac{q_{t}^{e}-q_{t}^{a}}{q_{t}^{e}}\right|$, reflects $i$ 's perceived penalty from unbalancing his bid so that his unit prices will not differ substantially from the norm (similar to the effects of risk aversion in Athey and Levin, 2001). The term $-\left(1-\beta_{+}\right) A_{+}-\left(1+\beta_{-}\right) A_{-}-(1-$ $\gamma) X-(1+\delta) D$ also influences the total markup $\left(\mathbf{b}^{i}-\mathbf{c}^{i}\right) \cdot \mathbf{q}^{a}$ on installing $\mathbf{q}^{a}$. To see this, suppose that the contractor expects a deduction of $\$ 1,000$. The first order condition suggests that the contractor will raise his bid by $(1+\delta)$ times $\$ 1,000$. Thus, the total costs of the deductions, as borne by the firm, are indirectly borne by the buyer, Caltrans.

Clearly, this model abstracts away from what are known to be fundamentally hard problems such as substituting the perfect foresight assumption on changes and actual quantities with a common values specification in which each bidder has signals of these variables. Despite these limitations, however, our first order conditions at a minimum generalize models previously imposed in both the theoretical and empirical literature, which implicitly impose the assumption that $\alpha=\beta_{+}=\beta_{-}=\gamma=\delta=0$. As we demonstrate shortly, this null hypothesis is strongly rejected by the data, and we will offer some evidence suggesting that adaptation costs of ex post changes may indeed be the reason.

\section{Data}

In the data, a unit of observation is a paving contract procured by Caltrans during 1999 and 2000. We index the projects by $n=1, \ldots, N$. Many of the variables in the theoretical section are directly measured in our data. We shall let a superscript $(n)$ index the value of one of these variables for project $n$. For instance, $b_{t}^{i,(n)}$ denotes the unit price for the $t^{t h}$ item submitted by bidder $i$ on project $n$. The sample 
includes $N=414$ projects with a value of $\$ 369.2$ million. ${ }^{14}$ There were a total of 1,938 bids submitted by 271 general contractors located primarily in California.

In Table 1, we list the top 25 contractors in our data set and their market share. Over half of the participating contractors, 157 firms, never won a contract during the period. In fact, only 5 firms participated in more than 10 percent of the auctions. To account for some of this asymmetry in size and experience, we will sometimes distinguish between "top" firms and "fringe" firms, where fringe firms are defined as those who each won less than 1 percent of the value of contracts awarded. We let $F R I N G E_{i}$ be a dummy variable equal to one if firm $i$ is a fringe firm. Tables 1 and 2 summarize the identities and market shares of the top firms, and Table 3 compares bidding by the top and fringe firms.

For each project, we have collected detailed information from the publicly available bid summaries and final payment forms that include the project number, the bidding date, the location of the job site, the estimated working days required for completion, and other information about the nature of the job. They also contain the identities of the bidders and their itemized bids. Projects are broken down into an average of 33 items, although one project has 255 items. For each item, we have the unit prices for all bidders, along with the estimated quantity. Additionally, the bid summaries report the engineer's estimate of the project's cost. This measure, provided to potential bidders before proposals are submitted, is intended to represent the "fair and reasonable price" the government expects to pay for the work to be performed. ${ }^{15}$ This estimate can be thought of as $\sum_{t} \bar{b}_{t} q_{t}^{e(n)}$, the dot product of "Blue Book" prices and the estimated quantities for project $n$. Caltrans measures $\bar{b}_{t}$ using the Blue Book prices contained in the Contract Item Cost Data Summaries, published by Caltrans’ Division of Office Engineer. We have merged this information into our data set. From the final payment forms, we collect data on the actual quantities, $q_{t}^{a(n)}$ used for each item. Additionally, the forms record the adjustments, extra work, and deductions that contribute to the total price of the project. These correspond to the variables $A^{(n)}, D^{(n)}$ and $X^{(n)}$ introduced in the previous section.

To account for the role that geographic proximity plays in determining a firm's transportation cost, we construct a measure of firm $i$ 's distance to the job site of project $n$, which we denote as $D I S T_{i}^{(n)}$. The contract provides information about the location of the project, often as detailed as the cross streets at which highway construction begins and ends. ${ }^{16}$ We combine this with the street address of each bidding firm, and record mileage and travel time as calculated by Mapquest's geographic search engine. Contractors

\footnotetext{
14 The size of the market is defined as the value of the winning bids for the projects in our data set. As we discussed in Section 2, this could be different than the final payments made to the contractors. We focus on those contracts for which asphalt constituted at least one third of the project's monetary value. We also exclude contracts that were not awarded to the lowest bidder. This is usually due to irregularities in the lowest submitted bid, bid relief granted to a contractor who claimed mistakes were made in his proposal, or other reasons for which the bidder was found to be ineligible. Such contracts represent only about 5 percent of all paving projects under consideration.

15 See the "Plans, Specifications, and Estimates Guide,” published by the Caltrans’ Division of Office Engineer for additional information about the formation of this estimate.

16 Where the location information is less precise, we use the city's centroid or a best estimate based on the post mile markers and highway names included on every contract.
} 
may have multiple locations or branch offices; when this is the case, the location closest to the job site is used. For those projects which cover multiple locations, we take the average of the distances and travel times to each location. Tables 4 and 5 summarize these calculated measures based on the ranking of bids. As expected, the contractors submitting the lowest bids also tend to have the shortest travel distances and times, reflecting their cost advantage.

It is clear that a firm's bidding behavior may be influenced by its production capacity and project backlog. In particular, firms that are working close to capacity may face a higher shadow price of free capacity when considering an additional job. Following the methods used by Porter and Zona (1993), we construct a measure of backlog from the record of winning bids, bidding dates, and project working days. We assume that work proceeds at a constant pace over the length of the project, and define the variable $B A C K L O G_{i}^{(n)}$ to be the remaining dollar value of projects won but not yet completed at the time a new bid is submitted. ${ }^{17}$ We then define $C A P A C I T Y_{i}^{(n)}$ as the maximum backlog experienced for any day during the sample period, and the utilization rate $U T I L_{i}^{(n)}$ as the ratio of backlog to capacity. For those firms that never won a contract, the backlog, capacity, and utilization rate are all set to $0 .{ }^{18}$

Discussions with members of the industry have revealed that firms may take into account their competitors' positions when devising their own bids. For this reason, we will include measures of their closest rival's distance and utilization rate. That is, since we treat the distance from the construction site as a proxy for cost advantage, we define $R D I S T_{i}^{(n)}$ as the minimum distance to the job site among bidders on project $n$, excluding firm $i$. Likewise, $R U T I L_{i}^{(n)}$ is the minimum utilization rate among bidders on project $n$, excluding firm $i$.

Summary statistics for the projects and the bids are provided in Tables 6, 7, and 8. There is noticeable heterogeneity in the size of projects awarded: the mean value of the winning bid is $\$ 3.2$ million with a standard deviation of $\$ 7.4$ million. The difference between the first and second lowest bids averages $\$ 191,516$, meaning that bidders leave some "money on the table.” On average, the projects require just over four months to complete, and during this period, it is clear that several change orders are processed. The final price paid for the work exceeds the winning bid by an average of $\$ 155,092$, or about 5.2 percent of the estimate. As Table 9 shows, a significant component of this discrepancy can be attributed to overruns and underruns on project items. Not only are there deviations in quantity, but large deviations also induce a correction to the item's total price, captured by the value of adjustments. In our sample, the mean

\footnotetext{
17 The measure of backlog was constructed using the entire set of asphalt concrete contracts, even though a few of these were excluded from the econometric analysis. Since we lack information from the previous year, the calculated backlog will underestimate the true activity of firms during the first few months of 1999; however, we believe the measure to be a good proxy.

18 In Bajari and Ye (2003) we demonstrated that the shadow value of capacity enters into the first order conditions like a deterministic cost shifter. This assumption is valid if bidders are indifferent about which of their competitors wins a project so that there is no incentive to strategically manipulate the capacities of competitors. Including a complete dynamic analysis of capacity utilization along with incomplete contracting is beyond the scope of this paper. See Pesendorfer and Jofre-Bonet (2003) for an analysis of capacity constrained bidders.
} 
adjustment is $\$ 135,032$. Compensation for extra work negotiated through after-contract change orders, as well as deductions, contribute to the difference, averaging $\$ 207,476$ and $-\$ 9,715$ respectively. Taken together, the size of these ex post changes suggests a sizeable degree of incompleteness in the original contracts.

\section{Empirical Analysis: Reduced Form Estimates}

\subsection{Standard Bid Regressions}

We begin our analysis by performing some reduced form regressions in order to determine which covariates best explain the total bids. A regression of the total estimated bid, $\mathbf{b}^{i,(n)} \cdot \mathbf{q}^{e,(n)}$, on the engineer's estimate, $\overline{\mathbf{b}}^{(n)} \cdot \mathbf{q}^{e,(n)}$ yields an $R^{2}$ of 0.987 and a coefficient almost exactly equal to 1 . This suggests that the engineering cost estimate is an unbiased predictor of the average total bid and can explain a large fraction of the variation of the bids in the data. This is consistent with previous papers that have studied this industry.

In Table 10, we regress the total estimated bid on various project characteristics. To correct for heteroskedasticity related to the overall size of the project, for each project $n$ we divide each bid $\mathbf{b}^{i,(n)} \cdot \mathbf{q}^{e,(n)}$ by the engineer's estimate. We denote this normalized variable as $N B I D^{(n)}$. The explanatory variables include firm $i$ 's distance to the job site, its utilization rate, the minimum rival distance, the minimum rival utilization rate and the number of firms that submit a bid for project $n$. In all of our regressions, distance and fringe status are significant and have positive signs as expected. In the first two columns, however, the overall measure of goodness of fit is not particularly high. In columns III and IV, we add project and firm fixed effects to the regression. The results suggest that both of these variables add considerably to goodness of fit, particularly project fixed effects. These effects capture characteristics of the job that are known to contractors but are unobserved in our data, such as the condition of the job site, the difficulty of the tasks, and economic conditions at the time bids are submitted.

While regressions such as those in Table 10 are common in the literature, equation (3) suggests that they are misspecified. A more appropriate reduced form regression would use $\mathbf{b}^{i,(n)} \cdot \mathbf{q}^{a,(n)}$ as the dependent variable since, as we have demonstrated earlier, the difference between $\mathbf{q}^{e,(n)}$ and $\mathbf{q}^{a,(n)}$ can be large. Furthermore, in addition to including variables that shift $i$ 's cost and the costs of its competitors, the right hand side of the regression should include anticipated change orders, deductions, and expected quantity overruns. Recall from Section 4 and Table 9 that ex post payment changes are sizeable. In our sample, the final payment typically differs from the winning bid by over 5 percent. These numbers suggest that by ignoring ex post changes, the total payment to the contractor is often severely mismeasured in the literature.

\subsection{Accounting for Changes and Adaptation Costs}

Our theoretical analysis suggests that the regressions in Table 10 suffer from two sources of misspecifi- 
cation. First, the dependent variable is the total estimated bid, $\mathbf{b}^{i} \cdot \mathbf{q}^{e}$, instead of the (expected) total bid, $\mathbf{b}^{i} \cdot \mathbf{q}^{a}$. Second, the regressions above ignore the anticipated changes to payments due to adjustments, extras and deductions. Based on equation (3), we re-specify the reduced form regression as follows:

$$
b^{i,(n)} \cdot q^{a,(n)}=\theta_{1} x_{i}^{(n)}+\theta_{2} A_{+}^{(n)}+\theta_{3} A_{-}^{(n)}+\theta_{4} X^{(n)}+\theta_{5} D^{(n)}+\varepsilon_{i}^{(n)}
$$

The $x_{i}^{(n)}$ are the same costs and competitive interactions terms that appear in the standard reduced form (e.g., distance, utilization rate, rival's distance, etc.). By comparison with equation (3), we see that consistent estimates of $\theta_{2}$ through $\theta_{5}$ can be used to derive estimates of the impact of on ex post contract changes:

$$
\begin{array}{ll}
\theta_{2} \equiv-\left(1-\beta_{+}\right) & \theta_{4} \equiv-(1-\gamma) \\
\theta_{3} \equiv-\left(1+\beta_{-}\right) & \theta_{5} \equiv-(1+\delta)
\end{array}
$$

The above regression is estimated by least squares. As in the previous reduced form bid regression, it is appropriate to correct for heteroskedasticity related to project size by dividing through by an estimate of that size. Since we are using variables that relate to individual items' quantities and prices, we would like to use a measure that is computed from these individual items. As mentioned in Section 4, we have access to an estimate for $\bar{b}_{t}$ from the Caltrans Cost Data Book. ${ }^{19}$

In Table 11, we present the results of this re-specified reduced form regression. The dependent variable, which we will refer to as $N A C T_{i}^{(n)}$, is the actual payment $\mathbf{b}_{i} \cdot \mathbf{q}^{a}$, divided by the project estimate. As columns I and II demonstrate, when we only include the firm's and its competitors' cost shifters as covariates, the results appear to be similar to Table 10. A firm's own distance and whether or not it is a fringe firm appear to be the most important predictors of $N A C T_{i}^{(n)}$. For a given project, fringe firms tend to bid slightly more than non-fringe firms. project fixed effects also absorb a great deal of variation in the bids, again suggesting that there is some unobserved project-specific heterogeneity. Note, however, that the regressions in Table 11, column III is almost identical the to regression in Table 10, column III. However, the $\mathrm{R}^{2}$ increases from 0.53 to 0.93 when we use the unit prices times the actual quantities as suggested by our first order conditions. We take this as evidence that using ex post information improves our ability to explain the observed bids considerably.

Next, we include the ex post changes. We use $N D E D^{(n)}$ and $N E X^{(n)}$ to denote the values of deductions and extra work, both normalized by dividing through by the project estimate (these account for $D$ and $X$ in the theoretical model). We distinguish between positive adjustments and negative adjustments to compensation, $N \operatorname{Pos} A d j{ }^{(n)}$ and $N N e g A d j{ }^{(n)}$, respectively (these account for $A_{+}$and $A_{-}$in the model). Because these characteristics do not vary within a given project, collinearity prevents us from including project fixed effects in the same regression with these other measures. The results of the regression without

19 Not all items have values in this source. To circumvent this problem, we derive an estimate for the missing $\bar{b}_{t}$ using the mean of the unit prices bid in all the contracts that appear in our data. Our method of averaging submitted bids to construct engineering estimates is similar to how they are constructed by professional estimating companies. This had an $R^{2}$ of 0.69 when regressed on the estimates we received from the Caltrans Cost Data Book. 
these fixed effects are shown in columns III and IV. Another way to deal with this collinearity is to run the fixed effect regression in two steps. First, we regress $N A C T^{(n)}$ on $D I S T_{i}^{(n)}, F R I N G E_{i}^{(n)}$, and project fixed effects. Then the estimates of the fixed effects are regressed on $N D E D^{(n)}, N E X^{(n)}, N P o s A d j(n)$ and $N N e g A d j^{(n)}$. This method allows us to consider the impact of ex post changes while still accounting for important project-specific unobservables. These results are presented in columns V and VI of Table 11. It is worth noting that the coefficients on $N D E D^{(n)}, N E X^{(n)}, N P o s A d j^{(n)}$ and $N N e g A d j(n)$ are almost identical with and without the fixed effects.

The results provide evidence that some form of frictions are imposed on the costs and revenues generated by ex post changes. For example, in column VI of Table 11, the coefficient on $N D E D^{(n)}$ is -7.36 which implies for our model that $\delta=6.36$. This suggests that if contractors expect an extra dollar of deduction, they will raise their bid by $\$ 6.36$ above and beyond the expected loss of $\$ 1$. This increase is a way for them to compensate for the expected loss from the additional costs of adaptation and renegotiation. As we discussed in Section 3, if contractors were risk neutral and there were no adaptation costs, the coefficient on deductions should be -1 . The fact that the coefficient is -7.36 is consistent with there being $\$ 6.36$ of adaptation costs for every dollar of deductions. On a job with a $\$ 6,118$ deduction (the median deduction assessed in our sample), this implies an increased cost to the state of almost $\$ 40,000$. For the 414 jobs that we study, this implies that deductions add $\$ 25,580,779$ in adaptation costs to the final price paid by the state.

A similar interpretation may be given to the coefficient of -3.80 on negative adjustments, $N N e g A d j(n)$. When engineers underestimate the quantity of an item required to complete the job, the state will often negotiate a negative adjustment with a contractor who has bid that item at a high per unit price. Our regression results suggest that these negotiations carry with them a $\$ 2.80$ adaptation cost for every dollar in adjustments. If bidders anticipate high downward adjustments of this sort, they tend to raise their bids, not only to recoup the expected loss, but also to recover the adaptation costs they must expend while haggling over price changes.

If there were no adaptation costs and if contractors were risk-neutral, we would expect to find coefficients on positive adjustments equal to -1 , implying that firms lower their bids by $\$ 1$ when they expect to receive an additional $\$ 1$ for work that has already been completed. The coefficient of 1.84 on positive adjustments implies that firms actually tend to raise their bids when they expect this additional compensation. One interpretation of this is that firms expect to spend $\$ 2.84$ in adaptation costs for every dollar they obtain in adjustment compensation. Similarly, the coefficient of $\$ 1.20$ on extra work implies that firms expect to spend $\$ 2.20$ in adaptation costs for every dollar they obtain in adjustment compensation. ${ }^{20}$

20 We note that our regressions imperfectly control for costs from extra work since these quantities associated with extra work are not directly observed by the econometrician. In our structural model, presented in the next section, we attempt to deal with this in two ways. First, we propose an IV strategy that exogenously shifts the payments from ex post changes. Also, we attempt to bound the potential bias from omitted costs. 
It is worth noting that the adjustment costs implied from deductions are higher than those implied by adjustments and extras. The natural interpretation through the lens of our model is that contractors require more upfront compensation when they expect funds to be deducted ex post, as opposed to adjustments and extras.

We now turn to the estimation of the penalty from skewing bids. To account for expected quantity changes, we include two alternative measures that serve as proxies. $P C T^{(n)}$ is the average of the percent quantity overruns on each item $t$ in a given project. Although this measure reflects upon the civil engineers' errors in estimation, it does not preserve the relative importance of contract items. A 10 percent overrun on a small item like milepost markers is quite different than a 10 percent overrun on a major item like asphalt concrete. To account for this we constructed another measure, NOverrun ${ }^{(n)}$, which is defined as the sum of the dollar overrun on individual items, divided by the project estimate. This dollar overrun is computed by multiplying the difference in the actual and estimated quantity by the item cost estimate reported in the Contract Cost Data Book, $\bar{b}_{t}$. Since not all contract items are contained in the data book, NOverrun ${ }^{(n)}$ should be thought of as a partial project overrun due to quantity changes in the more standard items.

Like in Athey and Levin (2001), we find that when contractors expect overruns they will actively skew their bids and their total payments will increase. The coefficients on both the percent overrun, $P C T^{(n)}$, and the partial dollar overrun on standard contract items, NOverrun ${ }^{(n)}$, are positive and significant. This is consistent with contractors giving skewed bids to increase their total payment without changing their probability of winning the job. In Table 12, we investigate the incentives to skew bids further by running a regression of item per-unit prices on the percent by which that particular item overran. The left hand side variable is the unit price divided by an engineer's estimate of the unit price. The coefficient on percent overrun is 0.027 , which is statistically significant at the $1 \%$ level. That is, if a contractor expected a ten percent overrun on some item, he would shade his bid up by approximately one quarter of one percent, a modest amount. When we allow for heteroskedasticity within an item code by using fixed or random item effects, the coefficient on percent overrun is similar, although with 2450 types of items, these individual effects do not add much explanatory power to the regression. ${ }^{21}$

We have argued that the standard reduced form bid function is misspecified because it ignores ex post changes in the contract, and it replaces actual quantities with estimated quantities. Despite the fact that our re-specified reduced form corrects for these omissions, it still suffers from several drawbacks.

First, in our data, the bidders will be uncertain about the magnitude of ex post changes. Therefore, the first order conditions should include the expected values of $N D E D^{(n)}, N E X^{(n)}, N P o s A d j^{(n)}$ and $N N e g A d j{ }^{(n)}$ instead of their actual values. The standard econometric analysis of measurement error suggests that our reduced form estimates of transactions costs will therefore be biased.

$21 \quad$ We might be worried that the regression in Table 12 is misspecified because it does not account for the fact that the expected and actual values of the variables may differ. Following logic used in the estimation of Euler equations, we also estimated these equations using variables in the current information set as instruments. The results were nearly identical. 
Second, our reduced form regressions imperfectly approximate the first order conditions. For instance, in the reduced form regressions, we attempt to capture market power by including $R D I S T_{i}^{(n)}$ and $R U T I L_{i}^{(n)}$ as regressors. However, the first order conditions imply that the probability of winning needs to be included in order to assess market power (e.g. the term $\left(\sum_{j \neq i} \frac{h_{j}\left(\mathbf{b}^{i} \cdot \mathbf{q}^{e}\right)}{1-H_{j}\left(\mathbf{b}^{i} \cdot \mathbf{q}^{e}\right)}\right)^{-1}$ ). Thus, the measurement of market power in the reduced form is misspecified and the interpretation of the regression coefficients is problematic as a result.

Third, the interpretation of the error term is unclear in the above reduced form regressions. As we shall discuss in the next section, the interpretation of the error term is subtle. Without a clear discussion of the error term, it is difficult to assess the plausibility of the instruments used for estimation.

In the next section, we shall discuss how to estimate the structural primitives of our model. An advantage of the structural approach is that it will allow us to assess the relative magnitude of three potential distortions: (i) rents from private information and market power (ii) skewed bidding and (iii) adaptation costs. While the structural model will use somewhat different econometric methods, we shall find a great deal of consistency with our reduced form results.

\section{Structural Estimation}

In this section, we propose a method for structurally estimating the model discussed in Section 3. The estimation approach builds on the two-step nonparametric estimators discussed in Elyakime, Laffont, Loisel and Vuong (1994), Guerre, Perrigne, and Vuong (2000) and Campo, Guerre, Perrigne and Vuong (2002). In the first step, we estimate the density and cdf of the bid distributions for project $n$, denoted by $h_{j}^{(n)}\left(\mathbf{b}^{i} \cdot \mathbf{q}^{e}\right)$ and $H_{j}^{(n)}\left(\mathbf{b}^{i} \cdot \mathbf{q}^{e}\right)$ respectively. In the second step, we estimate the penalty from skewed bidding, $\alpha$ and the adjustment cost coefficients, $\beta_{+}, \beta_{-}, \delta$ and $\gamma$. We do this by using the first order conditions in (3) to form a GMM estimator.

\subsection{Estimating Bid Distributions}

Much of the previous econometric literature is concerned with nonparametric estimation of $h_{j}$ and $H_{j}$. While a fully nonparametric approach is technically very elegant, it is not practical in our application. Since we wish to include measures of firm specific distance and other controls for cross firm heterogeneity, nonparametric approaches would suffer from a curse of dimensionality.

In our application, we will estimate $h_{j}^{(n)}\left(\mathbf{b}^{i} \cdot \mathbf{q}^{e}\right)$ and $H_{j}^{(n)}\left(\mathbf{b}^{i} \cdot \mathbf{q}^{e}\right)$ semiparametrically. We begin by first running a regression similar to those in Table 10:

$$
\frac{\mathbf{b}_{j}^{(n)} \cdot \mathbf{q}^{e,(n)}}{\overline{\mathbf{b}}^{(n)} \cdot \mathbf{q}^{e}}=x_{j}^{(n) \prime} \theta+u^{(n)}+\varepsilon_{j}^{(n)}
$$


where as before the dependent variable is the normalized estimated bid, and $x_{j}^{(n)}$ includes the firm's distance and whether or not it is a fringe firm. We also include an auction-specific fixed effect, $u^{(n)}$, to control for project-specific characteristics that are observed by the bidders but not the econometrician. As Krasnokutskaya (2004) has emphasized, failure to account for this form of unobserved heterogeneity may lead to a considerable bias in the structural estimates. As a robustness check we also estimated a version of the model with random effects and found little quantitative change in our results.

Let $\widehat{\theta}$ denote the estimated value of $\theta$ and let $\widehat{\varepsilon}_{j}^{(n)}$ denote the fitted residual. We will assume that the residuals to this regression are iid with distribution $G(\cdot)$. The iid assumption would be satisfied if costs had a multiplicative structure which we describe in detail in the next subsection. Under these assumptions, we observe that for project $n$ :

$$
\begin{aligned}
H_{j}^{(n)}(b) & \equiv \operatorname{Pr}\left(\frac{\mathbf{b}_{j}^{(n)} \cdot \mathbf{q}^{e,(n)}}{\overline{\mathbf{b}}^{(n)} \cdot \mathbf{q}^{e,(n)}} \leq \frac{b}{\overline{\mathbf{b}}^{(n)} \cdot \mathbf{q}^{e,(n)}}\right) \\
& =\operatorname{Pr}\left(x_{j}^{(n) \prime} \theta+u^{(n)}+\varepsilon_{j}^{(n)} \leq \frac{b}{\overline{\mathbf{b}}^{(n)} \cdot \mathbf{q}^{e,(n)}}\right) \equiv G\left(\frac{b}{\overline{\mathbf{b}}^{(n)} \cdot \mathbf{q}^{e,(n)}}-x_{j}^{(n) \prime} \theta-u^{(n)}\right) .
\end{aligned}
$$

That is, the distribution of the residuals, $\varepsilon_{j}^{(n)}$ can be used to derive the distribution of the observed bids. ${ }^{22}$ We estimate $G$ using the distribution of the fitted residuals $\widehat{\varepsilon}_{j}^{(n)}$, and then recover an estimate of $H_{j}^{(n)}(b)$ by substituting in this distribution in place of $G$. An estimate of $h_{j}^{(n)}(b)$ can be formed using similar logic. We note that both $H_{j}^{(n)}(b)$ and $h_{j}^{(n)}(b)$ will be estimated quite precisely because there are 1938 bids in our auction. Given the estimates $\widehat{H}_{j}^{(n)}$ and $\widehat{h}_{j}^{(n)}$ we generate an estimate for $\left(\sum_{j \neq i} \frac{\widehat{h}_{j}^{(n)}\left(\mathbf{b}_{i} \cdot \mathbf{q}^{e}\right)}{1-\widehat{H}_{j}^{(n)}\left(\mathbf{b}_{i} \cdot \mathbf{q}^{e}\right)}\right)^{-1}$.

\subsection{Estimating $\alpha, \beta_{+}, \beta_{-}, \delta$ and $\gamma$}

Next, we turn to the problem of estimating $\alpha, \beta_{+}, \beta_{-}, \delta$ and $\gamma$. We will assume that the distribution of private costs satisfies the following linear structure:

$$
\mathbf{c}_{i}^{(n)} \cdot \mathbf{q}^{a,(n)} \equiv \widetilde{c}_{i}^{(n)} \overline{\mathbf{b}}^{(n)} \cdot \mathbf{q}^{a,(n)} .
$$

That is, actual total costs can be represented as a scalar random variable $\widetilde{c}_{i}^{(n)}$, times the engineering estimate $\overline{\mathbf{b}}^{(n)} \cdot \mathbf{q}^{a,(n)}$. The assumption in (6) is similar to the multiplicative structure used in Krasnokutskaya (2004) and the location-scale models considered in Hong and Shum (2001) and Bajari and Hortacsu (2003). A similar assumption is also implicit in Hendricks, Pinkse and Porter (2003) where the authors normalize lots by tract size.

\footnotetext{
22 We include the fitted value of the fixed effect in order to control for omitted, auction specific heterogeneity. The fitted value of the fixed effect may be poorly estimated when the number of bidders is small and introduce bias into our estimates. However, the parameter estimates appeared to be more sensible than a model where they were not included.
} 
By substituting (6) into (3) and dividing by $\overline{\mathbf{b}}^{(n)} \cdot \mathbf{q}^{a,(n)}$ we can write

$$
\begin{aligned}
& \widetilde{c}_{i}^{(n)}=\left(\frac{1}{\overline{\mathbf{b}}^{(n)} \cdot \mathbf{q}^{a,(n)}}\right)\left(\mathbf{b}^{i,(n)} \cdot \mathbf{q}^{a,(n)}-\frac{q_{t}^{a,(n)}}{q_{t}^{e,(n)}}\left(\sum_{j \neq i} \frac{h_{j}^{(n)}\left(\mathbf{b}^{i,(n)} \cdot \mathbf{q}^{e,(n)}\right)}{1-H_{j}^{(n)}\left(\mathbf{b}^{i,(n)} \cdot \mathbf{q}^{e,(n)}\right)}\right)^{-1}\right) \\
& +\left(\frac{1}{\overline{\mathbf{b}}^{(n)} \cdot \mathbf{q}^{a,(n)}}\right)\left[\left(1-\beta_{+}\right) A_{+}^{(n)}+\left(1+\beta_{-}\right) A_{-}^{(n)}+(1-\gamma) X^{(n)}+(1+\delta) D^{(n)}\right] \\
& -\alpha\left(\frac{1}{\overline{\mathbf{b}}^{(n)} \cdot \mathbf{q}^{a,(n)}}\right)\left[\begin{array}{c}
\sum_{t}\left(b_{t}^{i,(n)}-\bar{b}_{t}\right)^{2}\left|\frac{q_{t}^{e,(n)}-q_{t}^{a,(n)}}{q_{t}^{e,(n)}}\right|- \\
\left(\frac{2\left(b_{t}^{i,(n)}-\bar{b}_{t}\right)}{q_{t}^{e,(n)}}\left|\frac{q_{t}^{e,(n)}-q_{t}^{a,(n)}}{q_{t}^{e,(n)}}\right|\right)\left(\sum_{j \neq i} \frac{h_{j}^{(n)}\left(\mathbf{b}^{i,(n)} \cdot \mathbf{q}^{e,(n)}\right)}{1-H_{j}^{(n)}\left(\mathbf{b}^{i,(n)} \cdot \mathbf{q}^{e,(n)}\right)}\right)^{-1}
\end{array}\right]
\end{aligned}
$$

We will also include two additional sources of error in equation (7). The first is that bidders may not have perfect foresight about $A_{+}^{(n)}, A_{-}^{(n)}, X^{(n)}$ and $D^{(n)}$. However, if bidders are risk neutral and have rational expectations, then the first order condition simply needs to be modified to include $E A_{+}^{(n)}, E A_{-}^{(n)}$, $E X^{(n)}$, and $E D^{(n)}$, the expected value of changes, instead of the actual values. In our data, we do not directly observe bidders' expectations. However, we will use well known strategies from the estimation of Euler Equations (described below) to estimate the model.

A second source of error is that $A_{+}^{(n)}, A_{-}^{(n)}, X^{(n)}$ and $D^{(n)}$ may be endogenous because there are omitted costs that are observed by the firms, but not accounted for in our cost estimate $\overline{\mathbf{b}}^{(n)} \cdot \mathbf{q}^{a,(n)}$. We will denote these costs as $\xi_{i}^{(n)}$. These costs are likely to be correlated with $A_{+}^{(n)}, A_{-}^{(n)}, X^{(n)}$ and $D^{(n)}$ since projects with large, ex post changes are likely to be more complicated and thus, more expensive to complete. We will use an IV approach to correct for the endogeneity of $A_{+}^{(n)}, A_{-}^{(n)}, X^{(n)}$ and $D^{(n)}$. In our data set, we observe the identity of the Caltrans engineer who supervised the project. The identity of the engineer will shift the ex post changes to the contract. While Caltrans highway contracts have numerous clauses devoted to changes, contractual incompleteness implies that Caltrans engineers have considerable discretion over the scope of changes and deductions, and the process through which these changes are governed. It is well known in the industry that there is considerable heterogeneity in a given engineer's propensity to make changes to the contract or impose deductions. Like in many fields, some engineers are naturally adept at dealing with difficult situations and solving disputes while others are not.

In order for the identity of the engineer to be a valid instrument, it must satisfy two conditions: (i) first it must be correlated with our endogenous variables and (ii) it must be uncorrelated with the error term. The first condition is fairly easy to verify. A regression of $A_{+}^{(n)}, A_{-}^{(n)}, X^{(n)}$ and $D^{(n)}$ on a full set of dummy variables for the engineer is highly significant, and explains 30 to 40 percent of the variation in these variables. This is robust to changes in specification of the model, such as normalizing the changes by the engineer's cost estimate, including additional covariates and restricting attention to engineers who appear many times in our sample

The second condition is not possible to verify directly since it is an identifying assumption. However, 
we shall argue that to a first approximation it is plausible. The first component of the error term are the expectational errors. By defnition, expectational errors must be uncorrelated with the identity of the engineer if the engineeer is known at time bidding occurs (which is typically the case). In fact, any variable know at the time of bidding is a valid instrument, as in rational expectations econometrics (see Hansen and Singleton (1982)). The intuition is simple- nothing known at the time of bidding can be correlated with the forecast error of payoff relevant variables. We also estimated the model with additional instruments (e.g. contemporaneous cost shifters such as fuel prices at the time of bidding) with similar results. Hence, our results are robust to the assumption that bidders imperfectly observe the engineer at the time of bidding.

Identification also requires that our instrument is mean independent of $\xi_{i}^{(n)}$. We argue that this is a reasonable assumption for several reasons. First, one might be worried that engineers predisposed to change the contract are assigned in a nonrandom way to more or less complicated projects. In our data, we find that the best predictor of the assignment of an engineer to a contract is which of the 12 district offices the engineer works at. In the data, 98 percent of the engineers work in a single district. However, district dummies do not predict $A_{+}^{(n)}, A_{-}^{(n)}, X^{(n)}$ and $D^{(n)}$. All districts apparently have, on average, a similar share of projects that experience large changes. Since there is a scarce supply of engineers in any given district, this will generate some exogeneity in how engineers are assigned to projects with many changes.

Another (informal) test of nonrandom assignment is to regress measures of engineer experience on ex post changes. In our data, we observe how many projects are assigned to a particular engineer, which we interpret as a proxy for experience or productivity. We regress this variable on $A_{+}^{(n)}, A_{-}^{(n)}, X^{(n)}$ and $D^{(n)}$. Nonrandom assignment would imply that these more experienced engineers are assigned to projects with more changes. However, the $\mathrm{R}^{2}$ this regression was less than 0.02 .

It is important to remember that the validity of our instrument is an identifying assumption that cannot be tested. Also, we would not be surprised if some component of unobserved cost is correlated with our instrument. However, our belief is that $\xi_{i}^{(n)}$ (which is anticipated at the time of bidding) is a less important source of error than the expectational errors. We have extremely detailed cost information, which is unusual for empirical IO. We observe all of the ex post units that are installed and have an engineering cost estimate for each item type. A regression of the total bid on the engineer's cost estimate, for instance, has an $\mathrm{R}^{2}$ of over 0.95 . We are able to explain much of the variation in bidding using our cost data and we observe inputs very well. On the other hand, things that are likely to go wrong in the future, and hence generate changes, we believe are difficult for bidders to forecast for great accuracy. We have only been able to explain about half the variation in ex post changes using our data.

If expectational errors are the main source of error, we believe that our instruments are quite plausible. External sources suggest that this industry is quite competitive. The publicly traded firms in our sample report margins of less than 3 percent and there is a large pool of potential entrants. It is hard to understand how a firm that poorly forecasted ex post changes compared to its peers would be able to survive in this 
market.

Given these our two additional sources of error, $\xi_{i}^{(n)}$ and expectational errors, we can rewrite (7) as:

$$
\begin{aligned}
& \widetilde{c}_{i}^{(n)}-\frac{\xi_{i}^{(n)}}{\overline{\mathbf{b}}^{(n)} \cdot \mathbf{q}^{a,(n)}}+\frac{1}{\overline{\mathbf{b}}^{(n)} \cdot \mathbf{q}^{a,(n)}}\left[\begin{array}{c}
\left(1-\beta_{+}\right)\left(A_{+}^{(n)}-E A_{+}^{(n)}\right)+\left(1+\beta_{-}\right)\left(A_{-}^{(n)}-E A_{-}^{(n)}\right)+ \\
(1-\gamma)\left(X^{(n)}-E X^{(n)}\right)+(1+\delta)\left(D^{(n)}-E D^{(n)}\right)
\end{array}\right] \\
= & \left(\frac{1}{\overline{\mathbf{b}}^{(n)} \cdot \mathbf{q}^{a,(n)}}\right)\left(\mathbf{b}^{i,(n)} \cdot \mathbf{q}^{a,(n)}-\frac{q_{t}^{a,(n)}}{q_{t}^{e,(n)}}\left(\sum_{j \neq i} \frac{h_{j}^{(n)}\left(\mathbf{b}^{i,(n)} \cdot \mathbf{q}^{e,(n)}\right)}{1-H_{j}\left(\mathbf{b}^{i,(n)} \cdot \mathbf{q}^{e,(n)}\right)}\right)^{-1}\right) \\
& +\left(\frac{1}{\overline{\mathbf{b}}^{(n)} \cdot \mathbf{q}^{a,(n)}}\right)\left[\left(1-\beta_{+}\right) A_{+}^{(n)}+\left(1+\beta_{-}\right) A_{-}^{(n)}+(1-\gamma) X^{(n)}+(1+\delta) D^{(n)}\right] \\
& -\alpha\left(\frac{1}{\overline{\mathbf{b}}^{(n)} \cdot \mathbf{q}^{a,(n)}}\right)\left[\begin{array}{c}
\sum_{t}\left(b_{t}^{i,(n)}-\bar{b}_{t}\right)^{2}\left|\frac{q_{t}^{e,(n)}-q_{t}^{a,(n)}}{q_{t}^{e,(n)}}\right|- \\
\left.\left(\frac{2\left(b_{t}^{i,(n)}-\bar{b}_{t}\right)}{q_{t}^{e,(n)}}\left|\frac{q_{t}^{e,(n)}-q_{t}^{a,(n)}}{q_{t}^{e,(n)}}\right|\right)\left(\sum_{j \neq i} \frac{h_{j}^{(n)}\left(\mathbf{b}^{i,(n)} \cdot \mathbf{q}^{e,(n)}\right)}{1-H_{j}^{(n)}\left(\mathbf{b}^{i,(n)} \cdot \mathbf{q}^{e,(n)}\right)}\right)^{-1}\right]
\end{array}\right.
\end{aligned}
$$

Equation (8) is identical to (7) except that we have brought over two additional sources of error to the left hand side. We will define $\widetilde{e}_{i}^{(n)}$ as:

$$
\widetilde{e}_{i}^{(n)}\left(\alpha, \beta_{+}, \beta_{-}, \delta, \gamma, h, H\right) \equiv \widetilde{c}_{i}^{(n)}-\frac{\xi_{i}^{(n)}}{\overline{\mathbf{b}}^{(n)} \cdot \mathbf{q}^{a,(n)}}+\frac{1}{\overline{\mathbf{b}}^{(n)} \cdot \mathbf{q}^{a,(n)}}\left[\begin{array}{c}
\left(1-\beta_{+}\right)\left(A_{+}^{(n)}-E A_{+}^{(n)}\right)+\left(1+\beta_{-}\right)\left(A_{-}^{(n)}-E A_{-}^{(n)}\right) \\
+(1-\gamma)\left(X^{(n)}-E X^{(n)}\right)+(1+\delta)\left(D^{(n)}-E D^{(n)}\right)
\end{array}\right]
$$

We will use (8) to form the moment condition below: ${ }^{23}$

$$
m_{N}(\alpha, \beta, \delta, \gamma, h, H)=\frac{1}{N} \sum_{n} \sum_{i} \widetilde{e}_{i}^{(n)}(\alpha, \beta, \delta, \gamma, h, H)\left(z_{i}^{(n)}-\bar{z}_{i}^{(n)}\right)
$$

where $z_{i}^{(n)}$ is the value of the instrument for bidder $i$ in auction $n .{ }^{24}$ We will also include the engineer's cost estimate as an instrument since it is a natural shifter of the bidding strategies and thus correlated with the right hand side variables in (8). We index the moment condition by $N$ to emphasize that the asymptotics of our problem depend on the number of auctions in our sample growing large.

The estimation strategy that we use follows Newey (1994). Let $\widehat{h}$ and $\widehat{H}$ denote a first stage estimate of the bid densities and distributions. Let $W$ be a positive semi-definite weight matrix. The estimator proposed by Newey is:

$$
(\widehat{\alpha}, \widehat{\beta}, \widehat{\delta}, \widehat{\gamma})=\arg \min m_{N}(\alpha, \beta, \delta, \gamma, \widehat{h}, \widehat{H})^{\prime} W m_{N}(\alpha, \beta, \delta, \gamma, \widehat{h}, \widehat{H})
$$

Newey demonstrates that under suitable regularity conditions this estimator has normal asymptotics despite depending on a nonparametric first stage. Furthermore, the asymptotic variance surprisingly does not depend on how the nonparametric first stage is conducted, as long as it is consistent. The optimal weighting matrix can be calculated by using the inverse of the sample variance of $m_{N}(\alpha, \beta, \delta, \gamma, \widehat{h}, \widehat{H})$ at a first stage estimate. In our application, the first stage estimates of $\widehat{h}$ and $\widehat{H}$ are quite precise given our regression

23 This follows from the moment condition that $\widetilde{e}_{i}^{(n)}$ and $z_{i}^{(n)}$ have a covariance of zero, i.e. $\operatorname{Cov}\left(\widetilde{e}_{i}^{(n)}, z_{i}^{(n)}\right)=0$.

24 Obviously, we can only use those engineers that supervise more than one project as an instrument. 
coefficients since there are over 1900 individual bids. Therefore, it is quite unlikely that our first stage bid density and distribution estimates introduce significant bias into the estimates. ${ }^{25}$

Given estimates $(\widehat{\alpha}, \widehat{\beta}, \widehat{\delta}, \widehat{\gamma})$, we can recover an estimate of contractors' implied markups. We estimate $\widehat{\mathbf{c}}^{i} \cdot \mathbf{q}^{a}$, contractor $i$ 's total cost for installing the actual quantities by evaluating the empirical analogue of (3):

$$
\begin{aligned}
\left(\mathbf{b}^{i,(n)}-\widehat{\mathbf{c}}^{i,(n)}\right) \cdot \mathbf{q}^{a,(n) ،}= & \frac{q_{t}^{a,(n)}-2 \hat{\alpha}\left(b_{t}^{i,(n)}-\bar{b}_{t}\right)\left|\frac{q_{t}^{a,(n)}-q_{t}^{e,(n)}}{q_{t}^{e,(n)}}\right|}{q_{t}^{e,(n)}}\left(\sum_{j \neq i} \frac{\hat{h}_{j}^{(n)}\left(\mathbf{b}^{i,(n)} \cdot \mathbf{q}^{e,(n)}\right)}{1-\hat{H}_{j}^{(n)}\left(\mathbf{b}^{i,(n)} \cdot \mathbf{q}^{e,(n)}\right)}\right)^{-1} \\
& +\hat{\alpha} \sum_{t}\left(b_{t}^{i,(n)}-\bar{b}_{t}\right)^{2}\left|\frac{q_{t}^{a,(n)}-q_{t}^{e,(n)}}{q_{t}^{e,(n)}}\right| \\
& -\left(1-\widehat{\beta}_{+}\right) A_{+}^{(n)}-\left(1+\widehat{\beta}_{-}\right) A_{-}^{(n)}-(1-\widehat{\gamma}) X^{(n)}-(1+\widehat{\delta}) D^{(n)}
\end{aligned}
$$

Using our estimates of $\widehat{H}, \widehat{h}, \widehat{\alpha}, \widehat{\beta}_{+}, \widehat{\beta}_{-}, \widehat{\gamma}$ and $\widehat{\delta}$, it is possible to evaluate the right hand side of the above equation since all of the terms are either data or are parameters that we have already estimated.

\subsection{Results}

We summarize the structural estimates in Tables 13-16. Table 13 reports the parameter values from our semiparametric GMM estimator. The adaptation cost estimates are similar to the reduced form estimates discussed in Section 5. For instance, the second column of Table 13 implies that every dollar the contractor receives for a positive adjustment generates $\$ 2.66$ of adaptation costs. Recall that our results control for the quantities that were actually installed by the contractor, $\overline{\mathbf{b}} \cdot \mathbf{q}^{a}$. Moreover, as we described in the previous section, we have instrumented for the endogeneity of positive adjustments to account for a possible bias from omitted cost variables. Therefore, we argue that this estimate reflects adaptation costs instead of omitted costs $\xi_{i}$. It is worth noting that our reduced form estimate from Table 11 was $\$ 2.84$ for this parameter, which is close.

Our other parameter estimates are also consistent with the presence of significant adaptation costs, and result in estimates that are similar to our initial reduced form estimates. A dollar of deductions generates $\$ 8.71$ in adaptation costs (\$6.36 in the reduced form) and a dollar of negative adjustments generates \$12.07 in adaptation costs. This last parameter is quite different from what we obtained in the reduced form estimates. That said, the average negative adjustments in our sample is only about $\$ 3149$ and the average negative deduction is $\$ 9,714$. Therefore, while the marginal effect of these variables are quite large, their

\footnotetext{
25 Admittedly, we potentially introduce a bias into our estimates through the inclusion of auction specific fixed effects. The inclusion of the fixed effects may introduce a nuisance parameter problem into our estimates. However, the strategies proposed in the literature for dealing with unobserved heterogeneity (e.g. Krasnokutskaya (2004)) are not straightforward to apply to our more complicated framework. We found the estimates that controlled for unobserved heterogeneity lead to lower implied markups than estimates without fixed effects, consistent with the biases found in Krasnokutskaya (2004). Despite their limitations, we find the fixed effect estimates more plausible. We also found that random effects generated similar results.
} 
total contribution to project costs is modest. The engineering staff at Caltrans would have an incentive to economize on negative adjustments and deductions if they believed these variables generate large adaptation costs as our estimates suggest.

The estimated value of the skewing parameter, $\alpha$ is $-2.2535 \mathrm{E}-06$. This estimate is statistically significant and different from the sign predicted by our theoretical model. However, it is extremely small in monetary terms and has no appreciable impact on profits or overall costs. The result that there are small penalties from skewing is quite robust to alternative specifications for the functional form of the skewing penalty penalty. However, recall from Section 4 that positive and negative adjustments are essentially due to renegotiating unit prices. As an empirical matter, it may be difficult to separately identify a quadratic effect of overruns and underruns, as captured in $\alpha$, from the linear effect captured in $\beta_{+}$and $\beta_{-}$.

In Tables 14a and 14b, we summarize our estimates of bidders markups. Our results suggest that the industry is quite competitive. The median profit margin is 3.6 percent for all bids and 11.9 percent for winning bids. We note that Granite Construction Inc. the largest bidder in our data is a publicly traded company and reports a net profit margin of 2.91 percent. The construction industry average according Standard and Poors is 1.9 percent. Profit margins based on SEC filings and our conception of profits differ in many respects. However, the available direct evidence on profit margins suggests that the construction industry is quite competitive and our results are consistent with this evidence.

As Tables 14a and 14b demonstrate, markups over direct costs $\left(\mathbf{b}^{i}-\mathbf{c}^{i}\right) \cdot \mathbf{q}^{a}$ are considerably higher than the profit margin. The median markup over direct costs, $\left(\mathbf{b}^{i}-\mathbf{c}^{i}\right) \cdot \mathbf{q}^{a}$ is $\$ 254,311$ for all bids and $\$ 491,083$ for winning bids. The ratio of the markup to the estimate for the median job is 18.1 percent for all bids and 29.2 percent for winning bids.

In Table 15, we compare the estimates in Table 14 with the estimated markups found using more standard

methods. Using our first stage estimates of $\hat{H}_{j}\left(\mathbf{b}_{i} \cdot \mathbf{q}^{e}\right)$ and $\hat{h}_{j}\left(\mathbf{b}_{i} \cdot \mathbf{q}^{e}\right)$, we evaluate the empirical analogue of equation (4), which is essentially the estimator discussed in Guerre, Perrigne and Vuong (2000). These results, summarized in Table 15, look similar to the total markups reported in the last two columns of Table $14 \mathrm{a}$ and $14 \mathrm{~b}$. The median total markup is $\$ 224,788$, or $12.1 \%$ of the estimate for winning bidders. This is almost exactly the median profit margin estimated in Table 14. By comparing the first order conditions of the two models, this should not be surprising. The only difference in the net profit margin under the two approaches should come from the skewing penalty and the discrepancies between estimated and actual item quantities. Ex post changes will shift the bid, changing what we refer to as the direct markup, but do not alter the contractors' net profit margins.

\section{Discussion}




\subsection{Lessons for Auction Design}

Our estimates imply some perhaps surprising lessons for the design of these highway procurement auctions. The first is that the existing system seems to do a good job of limiting rents and promoting competition in that the total markup is fairly modest. The median bidder in our sample of 1938 bids priced contract items so that, if he did win the project, he could expect a profit of $\$ 52,127$, or $3.6 \%$ of the estimate. More interesting, though, is how firms make such a markup. Item-level reduced form regressions suggested that firms shade their bids upward slightly when they expect a particular item to run over. Yet, there is another reason for them to raise their unit price and overall bids when contracts are incomplete. Because they expect to be penalized with deductions and downward adjustments in compensation, and because adaptation costs erode more than any positive gains through change orders, they skew their bids upward to extract high rents on prespecified project items. Among winning bidders, the median value of this direct markup, $\left(\mathbf{b}_{i}-\mathbf{c}_{i}\right) \cdot \mathbf{q}^{a}$, is 29.2 percent of the project estimate.

Second, our estimates imply that adaptation costs are important. Implied adaptation costs on different types of final payment changes range from two dollars to over ten dollars for every dollar in change. When considering the amount of money awarded and deducted after the initial contract is signed, these costs are significant by any standard. Table 16 reports a lower and an upper bound for the adaptation costs on each project. These bounds are determined based on the possible margins that firms may collect on extra work through change orders. The lower bound is calculated as $2.6602 A_{+}+12.0712\left|A_{-}\right|+1.5216 X+8.7111|D|$ and the upper bound is calculated as $2.6602 A_{+}+12.0712\left|A_{-}\right|+2.5216 X+8.7111|D|$. The upper and lower bound differ by the coefficient on extra work, $X$. Suppose that the contractor was able to earn a profit margin from renegotiating changes as reflected in $X$. Our upper bound on profits from renegotiating the contract was $\$ 1$ for every $\$ 1$ of changes in scope. This would imply that the adaptation costs for renegotiating $X$ were 2.5216 because firms receive an extra dollar of profits for every extra dollar in $X{ }^{26}$

The median estimate of adaptation costs is a significant component of costs by any standard. It has a lower bound of $14.6(8.3,20.9)$ percent of the estimate and an upper bound of $18.1(12.4,23.9)$ percent of the estimate. We conclude that adaptation costs account for a significant portion of total project costs. These numbers might be surprising in the context of the existing economics literature which has emphasized private information and moral hazard as the main sources of departures from efficiency in procurement.

However, this result is consistent with current thinking in Construction and Engineering Project Management. (See Bartholomew (1998), Clough and Sears (1994), Hinze (1993) and Sweet (1994). Also see Bajari and Tadelis (2001) for a more complete set of references and discussion of the literature). One of the central concerns emphasized in this literature are methods for minimizing the costs of disputes between

\footnotetext{
26 Industry sources suggest that a twenty percent profit margin on change orders is most common. It is helpful to recall that our cost estimate controls for the quantities actually installed and that positive and negative adjustments are effectively changes to compensation from the unit prices. Hence, these are a pure transfer and do not involve additional costs that we have not controlled for in our cost estimate.
} 
contractors and buyers. The topic of controlling contractor margins by comparison receives relatively little emphasis in this literature.

Our results suggest that the focus in the literature is appropriate for this industry. Contractor margins are estimated to be fairly modest. Apparently, competitive bidding and free entry do a good job of keeping profits low. Our results suggest that reducing adaptation cost is probably the most important source of potential improvements to efficiency. An implication of equation (3) is that Caltrans is ultimately responsible for expected adaptation costs on the project, as they are directly passed on from the bidders. Ex post changes that are anticipated do not change contractor profits or losses.

Summing over all 414 projects in our data, the lower bound suggests that Caltrans spent \$189 million on adaptation costs in 1999 and 2000. The average ratio of the adaptation costs to the winning bid is 0.1048. Even half of this number would be substantial. We note that our estimates do not account for the adaptation costs incurred by the buyer. Presumably, renegotiation with the contractor also requires additional staff and other resources. Including these additional costs would make the total estimate of adaptation costs even higher.

\subsection{Concluding Remarks}

Most of the existing literature on procurement is focused on designing a contract or auction that minimizes contractors' informational rents while giving appropriate incentives to minimize moral hazard. Taken literally, in this industry, our analysis suggests that a perhaps more important problem is to limit adaptation costs. These results are consistent with Bajari and Tadelis (2001) and Bajari, McMillan and Tadelis (2004) where we argued, heavily citing industry sources, that adaptation costs are a key determinant of contract form and award mechanism in private sector construction. We noted that in the private sector, open competitive bidding for fixed price contracts is only infrequently used because it is perceived to create large and inefficient levels of adaptation costs. We interpret our finding as further empirical evidence that adaptation costs are one of the leading disadvantages of the traditional competitive bidding system.

To the best of our knowledge, this is the first paper to use a structural model to recover estimates of adaptation costs. Our results suggest that these adaptation costs are an important determinant of observed bidding behavior. Therefore, structural models that fail to account for these costs might generate considerable biases in parameter estimates and estimated direct cost margins. Finally, our results suggest that commonly used reduced form bid functions are misspecified and thus biased when changes occur. The reduced form bid functions must control for ex post changes to the contract and the dependent variable should be the total bid using the actual quantities as weights. 


\section{References}

[1] Asker, John and Cantillon, Estelle. "Properties of Scoring Auctions.” Centre for Economic Policy Research Discussion Paper No. 4734, November 2004.

[2] Athey, Susan and Levin, Jonathan. "Information and Competition in U.S. Forest Service Timber Auctions.” Journal of Political Economy, April 2001, 109(2), pp. 375-417.

[3] Athey, Susan, Levin, Jonathan and Seira, Enrique, "Comparing Open and Sealed Bid Auctions: Theory and Evidence from Timber Auctions,” Stanford University Working Paper, September 2004.

[4] Bajari, Patrick and Hortacsu, Ali "The Winner's Curse, Reserve Prices and Endogenous Entry: Empirical Insights from eBay Auctions.” The Rand Journal of Economics, Summer 2003 3(2), 329-355.

[5] Bajari, Patrick; McMillan, Robert and Tadelis, Steve. "Auctions versus Negotiations in Procurement: An Empirical Analysis.” Working paper, Stanford University, June 2004.

[6] Bajari, Patrick and Tadelis, Steve. "Incentives Versus Transaction Costs: A Theory of Procurement Contracts.” RAND Journal of Economics, Autumn 2001, 32(3), pp. 287-307.

[7] Bajari, Patrick and Ye, Lixin. "Deciding Between Competition and Collusion.” Review of Economics and Statistics, November 2003, 85(4), pp. 971-89.

[8] Bartholomew, Stuart H. Construction Contracting: Business and Legal Principles. Upper Saddle River, NJ: Prentice-Hall, Inc., 1998.

[9] Brooker, Penny. "Survey of Construction Lawyers' Attitudes and Practice in the Use of ADR in Contractor’s Disputes.” Construction Management and Economics, 1999, 17, pp. 757-765.

[10] Bushnell, James and Oren, Shmuel. "Bidder Cost Revelation in Electric Power Auctions.” Journal of Regulatory Economics, February 1994, 6(1), pp. 5-26.

[11] Campo, Sandra. "Attitudes Towards Risk and Asymmetric Bidding: Evidence from Construction Procurements.” Working Paper, University of North Carolina at Chapel Hill, 2004.

[12] Campo, Sandra; Guerre, Emmanuel; Perrigne, Isabelle and Vuong, Quang. "Semiparametric Estimation of First-Price Auctions with Risk Averse Bidders.” Working paper, University of Southern California, November 2002.

[13] Cantillon, Estelle and Pesendorfer, Martin. “Combination Bidding in Multi-Unit Auctions.” Mimeo, London School of Economics, June 2004.

[14] Chakravarty, Surajeet and MacLeod, W. Bentley. “On the Efficiency of Standard Form Contracts: The Case of Construction.” Working Paper 17, University of Southern California Law and Economics Work- 
ing Paper Series, September 2004.

[15] Che, Yeon-Koo. "Design Competition through Multi-dimensional Auctions.” RAND Journal of Economics, Winter 1993, 24(4), pp. 668-80.

[16] Clough, Richard H. and Sears, Glenn A. Construction Contracting, 6th ed. New York: Wiley, 1994.

[17] Corts, Kenneth and Singh, Jasjit. "The Effect of Repeated Interaction on Contract Choice: Evidence from Offshore Drilling.” Journal of Law, Economics and Organization, April 2004, 20(1), pp. 230-60.

[18] Crocker, Keith J. and Reynolds, Kenneth J. "The Efficiency of Incomplete Contracts: An Empirical Analysis of Air Force Engine Procurement.” RAND Journal of Economics, Spring 1993, 24(1), pp. 126-46.

[19] Donald, Stephen G. and Paarsch, Harry J. "Piecewise Pseudo-Maximum Likelihood Estimation in Empirical Models of Auctions,” International Economic Review, 1993, 34, pp. 121-148.

[20] Elyakime, Bernard; Laffont, Jean-Jacques; Loisel, Patrice and Vuong, Quang. "First-Price Sealed-Bid Auctions with Secret Reservation Prices.” Annales D’Economie et de Statistique, 1994, 34, 115-41.

[21] Guerre, Emmanuel; Perrigne, Isabelle and Vuong, Quang. “Optimal Nonparametric Estimation of First-Price Auctions.” Econometrica, May 2000, 68(3), pp. 525-74.

[22] Hanna, Awad S. and Gunduz, Murat. "Impact of Change Orders on Small Labor-Intensive Projects.” Journal of Construction Engineering and Management, September/October 2004, 130(5), pp. 726-733.

[23] Hansen, Lars P. and Singleton, Kenneth J. “Generalized Instrumental Variables Estimation of Nonlinear Rational Expectations Models.” Econometrica, 1982, 50:5 pp. 1269-1286.

[24] Hendricks, Kenneth; Pinkse, Joris and Porter, Robert H. "Empirical Implications of Equilibrium Bidding in First-Price, Symmetric, Common-Value Auctions.” Review of Economic Studies, January 2003, 70, pp. 115-46.

[25] Hester, Weston T.; Kuprenas, John A. and Chang, T.C. "Construction Changes and Change Orders: Their Magnitude and Impact,” Source Document 66, Construction Industry Institute, October 1991.

[26] Hinze, Jim. Construction Contracts, McGraw-Hill Series in Construction Engineering and Project Management. Boston: Irwin/McGraw-Hill, 1993.

[27] Hong, Han and Shum, Matthew. "Increasing Competition and the Winner's Curse: Evidence from Procurement.” Review of Economic Studies, October 2002, 69, pp. 871-98.

[28] Ibbs, C. William; Lee, Stephanie A. and Li, Michael I. "Fast-Tracking’s Impact on Project Change.” Project Management Journal, December 1998, 29(4), pp. 35-42. 
[29] Ibbs, C.W., Wall, D.E., Hassanein, M.A., Back,W.E., De La Garza, J.M., Twardock, R.K., Kim, J.J., and Schran, S.M. "Determining the Impact of Various Construction Contract Types and Clauses on Project Performance: Volumes I and II.” Documents SD-10 and SD-11, Austin, Tex.: The Construction Industry Institute, 1986.

[30] Krasnokutskaya, Elena. "Identification and Estimation in Highway Procurement Auctions under Unobserved Auction Heterogeneity.” Working paper 05-006, University of Pennsylvania, May 2004.

[31] Krasnokutskaya, Elena and Seim, Katja. "Determinants of the Participation Decision in Highway Procurement Auctions.” Working paper, University of Pennsylvania and Stanford Graduate School of Business, 2004.

[32] Laffont, Jean J. and Tirole, Jean. A Theory of Incentives in Procurement and Regulation. Cambridge, Mass.: MIT Press, 1993.

[33] Loosemore, Martin. "Bargaining Tactics in Construction Disputes.” Construction Management and Economics, 1999, 17, pp. 177-188.

[34] Masten, Scott E. “The Organization of Production: Evidence from the Aerospace Industry.” Journal of Law and Economics, October 1984, 27(2), pp. 403-17.

[35] Milgrom, Paul. “Employment Contracts, Influence Activities, and Efficient Organization Design.” The Journal of Political Economy, February 1988, 96(1), pp. 42-60.

[36] Moselhi, Osama; Assem, Ihab and El-Rayes, Khaled. "Change Orders Impact on Labor Productivity.” Journal of Construction Engineering and Management, March 2005, 131(3), pp. 354-359.

[37] Newey, Whitney K. “The Asymptotic Variance of Semiparametric Estimators.” Econometrica, November 1994, 62(6), pp. 1349-82.

[38] Osband, Kent and Reichelstein, Stefan. “Information-eliciting Compensation Schemes.” Journal of Public Economics, June 1985, 27(1), pp. 107-15.

[39] Paarsch, Harry J. "Deciding between the Common and Private Value Paradigms in Empirical Models of Auctions,” Journal of Econometrics, January-February 1992, 51(1), pp. 191-215.

[40] Pakes, Ariel. “Common Sense and Simplicity in Empirical Industrial Organization.” National Bureau of Economic Research Working Paper No. 10154, December 2003.

[41] Pesendorfer, Martin and Jofre-Bonet, Mireia. “Estimation of a Dynamic Auction Game.” Econometrica, September 2003, 71(5), pp. 1443-89.

[42] Porter, Robert H. and Zona, J. Douglas. “Detection of Bid Rigging in Procurement Auctions.” Journal of Political Economy, June 1993, 101(3), pp.518-38. 
[43] Sweet, Justin. Legal Aspects of Architecture, Engineering and the Construction Process, 5th ed. MinneapolisSt. Paul, MN: West Publishing Company, 1994.

[44] Williamson, Oliver E. Markets and Hierarchies. New York: Free Press, 1975.

[45]__ . The Economic Institutions of Capitalism. New York: Free Press, 1985. 
Table 1: Identities of Top 25 Firms

\begin{tabular}{|c|c|c|c|c|c|}
\hline $\begin{array}{c}\text { Firm } \\
\text { ID }\end{array}$ & Firm Name & $\begin{array}{l}\text { Market } \\
\text { Share }\end{array}$ & $\begin{array}{c}\text { Firm } \\
\text { ID }\end{array}$ & Firm Name & $\begin{array}{c}\text { Market } \\
\text { Share }\end{array}$ \\
\hline 104 & Granite Construction Company & $27.2 \%$ & 82 & Excel Paving Company & $1.5 \%$ \\
\hline 75 & E L Yeager Construction Co Inc & $10.4 \%$ & 186 & Pavex Construction & $1.3 \%$ \\
\hline 135 & Kiewit Pacific Co & $6.6 \%$ & 184 & Parnum Paving Inc & $1.2 \%$ \\
\hline 147 & M C M Construction Inc & $6.5 \%$ & 23 & Baldwin Contracting Company Inc & $1.1 \%$ \\
\hline 125 & J F Shea Co Inc & $3.3 \%$ & 162 & Mercer Fraser Company & $1.0 \%$ \\
\hline 244 & Teichert Construction & $3.3 \%$ & 248 & Tidewater Contractors Inc & $1.0 \%$ \\
\hline 262 & W Jaxon Baker Inc & $2.9 \%$ & 22 & B E C Construction Co & $0.9 \%$ \\
\hline 12 & All American Asphalt & $2.2 \%$ & 126 & J McLoughlin Engineering Co Inc & $0.8 \%$ \\
\hline 251 & Tullis And Heller Inc & $2.1 \%$ & 88 & Ford Construction Co Inc & $0.8 \%$ \\
\hline 237 & Sully Miller Contracting Co & $1.9 \%$ & 96 & George Reed Inc & $0.7 \%$ \\
\hline 265 & West Coast Bridge Inc & $1.9 \%$ & 87 & FNF Construction & $0.7 \%$ \\
\hline 25 & Banshee Construction Co Inc & $1.8 \%$ & 253 & Union Asphalt Inc & $0.7 \%$ \\
\hline 107 & Griffith Company & $1.6 \%$ & & TOTAL & $83.6 \%$ \\
\hline
\end{tabular}

There were a total of 125 active bidders for asphalt concrete construction contracts in 1999. The firms listed above are the top 25 firms, ranked according to their market share, i.e. the share of total contract dollars awarded.

Table 2: Bidding Activities of Top 25 Firms

\begin{tabular}{|c|c|c|c|c|c|c|c|c|c|}
\hline \multirow[t]{2}{*}{ ID } & \multirow{2}{*}{$\begin{array}{c}\text { No. } \\
\text { of } \\
\text { Wins }\end{array}$} & \multirow{2}{*}{$\begin{array}{l}\text { Total Bid } \\
\text { for } \\
\text { Contracts } \\
\text { Awarded }\end{array}$} & \multirow{2}{*}{$\begin{array}{c}\text { Final } \\
\text { Payments } \\
\text { on Contracts } \\
\text { Awarded }\end{array}$} & \multirow{2}{*}{$\begin{array}{c}\text { No. of } \\
\text { Bids } \\
\text { Entered }\end{array}$} & \multirow{2}{*}{$\begin{array}{c}\text { Participation } \\
\text { Rate }\end{array}$} & \multicolumn{4}{|c|}{ Conditional on Bidding for a Contract } \\
\hline & & & & & & $\begin{array}{l}\text { Average } \\
\text { Bid }\end{array}$ & $\begin{array}{c}\text { Average } \\
\text { Engineer's } \\
\text { Estimate }\end{array}$ & $\begin{array}{l}\text { Average } \\
\text { Distance } \\
\text { (Miles) }\end{array}$ & $\begin{array}{l}\text { Average } \\
\text { Time to } \\
\text { Job Site } \\
\text { (Min) }\end{array}$ \\
\hline 104 & 76 & $343,987,526$ & $378,629,804$ & 244 & $58.9 \%$ & $3,966,908$ & $3,928,872$ & 36.6 & 47.4 \\
\hline 75 & 13 & $132,790,460$ & $144,975,251$ & 31 & $7.5 \%$ & $8,607,538$ & $8,610,249$ & 61.0 & 70.6 \\
\hline 135 & 5 & $112,057,627$ & $92,031,048$ & 30 & $7.2 \%$ & $15,254,801$ & $14,798,046$ & 151.5 & 158.9 \\
\hline 147 & 2 & $89,344,972$ & $90,384,704$ & 6 & $1.4 \%$ & $21,952,372$ & $22,397,538$ & 72.6 & 77.8 \\
\hline 125 & 9 & $43,030,861$ & $46,506,051$ & 40 & $9.7 \%$ & $3,710,768$ & $3,512,680$ & 91.3 & 108.4 \\
\hline 244 & 16 & $40,177,076$ & $45,533,624$ & 43 & $10.4 \%$ & $3,104,075$ & $2,915,690$ & 40.6 & 52.3 \\
\hline 262 & 13 & $37,702,631$ & $40,808,024$ & 65 & $15.7 \%$ & $3,236,153$ & $3,293,634$ & 141.8 & 170.0 \\
\hline 12 & 14 & $30,764,962$ & $30,726,217$ & 33 & $8.0 \%$ & $2,425,688$ & $2,429,789$ & 24.0 & 29.7 \\
\hline 251 & 10 & $27,809,535$ & $28,651,380$ & 16 & $3.9 \%$ & $2,406,761$ & $2,612,752$ & 32.2 & 38.9 \\
\hline 237 & 17 & $27,889,186$ & $27,025,850$ & 49 & $11.8 \%$ & $2,389,932$ & $2,386,667$ & 54.4 & 59.9 \\
\hline 265 & 4 & $26,786,493$ & $26,426,965$ & 9 & $2.2 \%$ & $7,283,186$ & $7,406,581$ & 234.5 & 214.4 \\
\hline 25 & 2 & $23,118,363$ & $24,624,599$ & 7 & $1.7 \%$ & $5,448,318$ & $5,467,099$ & 40.4 & 43.3 \\
\hline 107 & 8 & $21,981,980$ & $22,706,554$ & 26 & $6.3 \%$ & $3,524,629$ & $3,758,627$ & 36.1 & 42.6 \\
\hline 82 & 3 & $17,763,635$ & $20,315,232$ & 33 & $8.0 \%$ & $2,045,813$ & $1,907,715$ & 24.2 & 28.7 \\
\hline 186 & 7 & $17,160,757$ & $18,050,388$ & 22 & $5.3 \%$ & $1,809,050$ & $1,719,094$ & 25.2 & 28.7 \\
\hline 184 & 12 & $14,997,849$ & $17,196,784$ & 25 & $6.0 \%$ & $1,780,978$ & $1,869,706$ & 84.6 & 106.9 \\
\hline 23 & 5 & $14,178,601$ & $15,726,516$ & 21 & $5.1 \%$ & $2,927,704$ & $2,746,659$ & 47.3 & 63.7 \\
\hline 162 & 8 & $12,379,191$ & $13,483,870$ & 17 & $4.1 \%$ & $1,557,772$ & $1,570,402$ & 37.0 & 47.5 \\
\hline 248 & 3 & $11,256,234$ & $13,258,546$ & 3 & $0.7 \%$ & $3,752,078$ & $4,588,278$ & 10.0 & 14.0 \\
\hline 22 & 7 & $11,855,713$ & $12,664,796$ & 10 & $2.4 \%$ & $2,333,166$ & $2,215,831$ & 98.7 & 128.1 \\
\hline 126 & 2 & $11,258,867$ & $11,390,486$ & 18 & $4.3 \%$ & $1,765,946$ & $1,801,236$ & 56.1 & 55.4 \\
\hline 88 & 1 & $9,674,380$ & $10,711,489$ & 2 & $0.5 \%$ & $8,567,932$ & $8,500,931$ & 87.5 & 102.5 \\
\hline 96 & 6 & $9,244,215$ & $10,290,260$ & 18 & $4.3 \%$ & $1,572,904$ & $1,551,537$ & 33.5 & 52.7 \\
\hline 87 & 1 & $10,498,536$ & $10,153,836$ & 13 & $3.1 \%$ & $12,431,695$ & $12,434,916$ & 388.2 & 380.9 \\
\hline 253 & 6 & $9,042,273$ & $9,394,612$ & 12 & $2.9 \%$ & $2,279,318$ & $2,466,966$ & 38.8 & 46.1 \\
\hline
\end{tabular}


Table 3: Comparison Between Fringe Firms and Firms with Over 1\% Market Share

\begin{tabular}{lrr}
\hline \hline & Fringe Firms & Non-Fringe Firms \\
\hline Number of Firms & 254 & 17 \\
Number of Wins & 198 & 216 \\
Number of Bids Submitted & 1238 & 700 \\
Average Bid Submitted & $\$ 3,389,984.75$ & $\$ 5,404,392.50$ \\
Average Distance to Job Site (miles) & 79.0 & 70.5 \\
Average Travel Time to Job Site (minutes) & 87.5 & 79.0 \\
Average Capacity & $\$ 949,141.10$ & $\$ 33,243,336.00$ \\
Average Backlog at Time of Bid & $\$ 126,114.10$ & $\$ 7,725,654.00$ \\
\hline The above averages were calculated by first calculating the average for each \\
bidder, then averaging these means over the fringe and non-fringe firms, respectively.
\end{tabular}

Table 4: Distance to Job Site (in miles)

\begin{tabular}{lrrrr|lrrrr}
\hline \hline & Mean & Std. Dev. & Min & Max & & Mean & Std. Dev. & Min & Max \\
\hline DIST1 & 47.47 & 60.19 & 0.27 & 413.18 & DIST6 & 88.21 & 115.84 & 0.74 & 695.43 \\
DIST2 & 73.55 & 100.38 & 0.19 & 679.14 & DIST7 & 88.46 & 119.97 & 0.85 & 570.27 \\
DIST3 & 75.47 & 95.56 & 0.13 & 594.16 & DIST8 & 73.91 & 75.85 & 4.47 & 259.09 \\
DIST4 & 84.38 & 89.87 & 1.45 & 494.08 & DIST9 & 105.86 & 104.31 & 3.41 & 495.67 \\
DIST5 & 76.12 & 86.33 & 1.25 & 513.31 & DIST10 & 69.72 & 80.20 & 7.35 & 294.97 \\
\hline
\end{tabular}

DIST1 is the distance of the lowest bidder, DIST2 is the distance of the second lowest bidder, and so on.

Table 5: Travel Time to Job Site (in minutes)

\begin{tabular}{|c|c|c|c|c|c|c|c|c|c|}
\hline & Mean & Std. Dev. & Min & Max & & Mean & Std. Dev. & Min & Max \\
\hline TIME1 & 56.95 & 64.28 & 1.00 & 411.00 & TIME6 & 97.28 & 119.61 & 2.00 & 767.00 \\
\hline TIME2 & 82.51 & 97.51 & 1.00 & 614.00 & TIME7 & 97.30 & 119.11 & 1.00 & 530.00 \\
\hline TIME3 & 85.86 & 97.44 & 0.00 & 580.00 & TIME8 & 85.81 & 79.78 & 8.00 & 267.00 \\
\hline TIME4 & 94.04 & 89.82 & 4.00 & 449.00 & TIME9 & 117.42 & 105.33 & 7.00 & 509.00 \\
\hline TIME5 & 85.92 & 85.39 & 5.00 & 458.00 & TIME10 & 81.56 & 80.97 & 12.00 & 287.00 \\
\hline
\end{tabular}

TIME1 is the distance of the lowest bidder, TIME2 is the distance of the second lowest bidder, and so on.

Table 6: Bid Concentration Among Contracts Awarded to Lowest Bidder

\begin{tabular}{l|ccccccccccc}
\hline \hline Number of Bidders & 2 & 3 & 4 & 5 & 6 & 7 & 8 & 9 & 10 & $11+$ & Total \\
\hline Contracts in 1999 & 21 & 47 & 36 & 30 & 11 & 8 & 4 & 2 & 3 & 0 & 162 \\
Contracts in 2000 & 31 & 46 & 49 & 43 & 31 & 19 & 8 & 12 & 6 & 7 & 252 \\
\hline
\end{tabular}

Table 7: Project Distribution throughout the Year

\begin{tabular}{lcccccccccccc}
\hline \hline Month & Jan & Feb & Mar & Apr & May & Jun & Jul & Aug & Sept & Oct & Nov & Dec \\
\hline Contracts in 1999 & 13 & 11 & 19 & 12 & 18 & 18 & 24 & 20 & 13 & 4 & 8 & 2 \\
Contracts in 2000 & 12 & 14 & 23 & 36 & 16 & 26 & 10 & 39 & 25 & 22 & 20 & 9 \\
\hline
\end{tabular}


Table 8: Summary Statistics

\begin{tabular}{lrrrrr}
\hline \hline & Obs & Mean & Std. Dev. & Min & Max \\
\hline Across Contracts Under Consideration & & & & & \\
\hline Winning Bid & 414 & $3,203,130$ & $7,384,337$ & 70,723 & $86,396,096$ \\
Markup: (Winning Bid-Estimate)/Estimate & 414 & -0.0617 & 0.1763 & -0.6166 & 0.7851 \\
Normalized Bid: Winning Bid/Estimate & 414 & 0.9383 & 0.1763 & 0.3834 & 1.7851 \\
Second Lowest Bid & 414 & $3,394,646$ & $7,793,310$ & 84,572 & $92,395,000$ \\
Money on the Table: Second Bid-First Bid & 414 & 191,516 & 477,578 & 68 & $5,998,904$ \\
Normalized Money on the Table: & 414 & 0.0679 & 0.0596 & 0.0002 & 0.3476 \\
(Second Bid-First Bid)/Estimate & 414 & 4.68 & 2.30 & 2 & 19 \\
Number of Bidders & 414 & 47.47 & 60.19 & 0.27 & 413.18 \\
Distance of the Winning Bidder & 414 & 56.95 & 64.28 & 1.00 & 411.00 \\
Travel Time of the Winning Bidder & 414 & 0.1206 & 0.1951 & 0.0000 & 0.9457 \\
Utilization Rate of the Winning Bidder & 414 & 73.55 & 100.38 & 0.19 & 679.14 \\
Distance of the Second Lowest Bidder & 414 & 82.51 & 97.51 & 1.00 & 614.00 \\
Travel Time of the Second Lowest Bidder & 414 & 0.1401 & 0.2337 & 0.000 & 0.9959 \\
Utilization Rate of the Second Lowest Bidder & & & & & \\
\hline Across Bids Submitted & 1938 & 1.0474 & 0.2685 & 0.3834 & 7.8611 \\
\hline Normalized Bid & 1938 & 72.37 & 91.93 & 0.13 & 695.43 \\
Distance to Job Site & 1938 & 81.93 & 92.29 & 0.00 & 767.00 \\
Travel Time to Job Site & 1938 & $5,453,880$ & $16,433,078$ & 0.00 & $1.503 \mathrm{e}+08$ \\
Backlog at Time of Bid & 1938 & $25,590,740$ & $49,856,236$ & 0.00 & $1.510 \mathrm{e}+08$ \\
Capacity & 1938 & 0.1221 & 0.2266 & 0.0000 & 0.9965 \\
Utilization (Backlog/Capacity) & 1938 & 26.70 & 36.60 & 0.13 & 618.62 \\
Minimal Distance Among Rivals & 1938 & 35.15 & 41.98 & 0.00 & 592.00 \\
Minimal Travel Time Among Rivals & 1938 & 0.0226 & 0.0894 & 0.0000 & 0.9806 \\
Minimal Utilization Among Rivals & & & & &
\end{tabular}

Table 9: Importance of Ex-Post Changes

\begin{tabular}{lrrrrr}
\hline \hline & Obs & Mean & Std. Dev. & Min & Max \\
\hline Adjustments & 414 & 135,032 & 681,068 & $-178,183$ & $12,142,414$ \\
Adjustments / Estimate & 414 & 0.0242 & 0.0493 & -0.2172 & 0.3962 \\
Extra Work & 414 & 207,476 & 706,372 & 0 & $12,271,703$ \\
Extra Work / Estimate & 414 & 0.0628 & 0.0837 & 0 & 0.5960 \\
Deductions & 414 & $-9,715$ & 47,933 & $-796,071$ & 0 \\
Deduction / Estimate & 414 & -0.0027 & 0.0093 & -0.0698 & 0 \\
CCDB Overrun = (ActQ-EstQ)*CCDB price & 414 & $-67,040$ & 502,017 & $-9,462,806$ & 506,575 \\
CCDB Overrun / Estimate & 414 & -0.0327 & 0.3186 & -6.3401 & 0.1610 \\
Final Payment-Winning Bid & 414 & 155,092 & $1,503,604$ & $-24,111,356$ & $13,747,552$ \\
(Final Payment-Winning Bid) / Estimate & 414 & 0.0523 & 0.1249 & -0.6591 & 0.6530 \\
\hline
\end{tabular}

The CCDB Overrun is meant to reflect the dollar overrun due to quantities that were misestimated during the procurement process. It is only a partial measure of the quantity-related overrun, since some of the nonstandard contract items do not have a corresponding price estimate from the Contract Cost Data Book (CCDB). The engineer's estimate was used to normalize this and the other measures. 
Table 10: Standard Bid Function Regressions

\begin{tabular}{|c|c|c|c|c|c|}
\hline Variable & I. & II. & III. & IV. & $\mathrm{V}$. \\
\hline $\operatorname{DIST}_{\mathrm{i}}^{(\mathrm{n})}$ & $\begin{array}{c}0.00019 \\
(322)\end{array}$ & $\begin{array}{c}0.00019 \\
(3.09)\end{array}$ & $\begin{array}{c}0.00019 \\
(385)\end{array}$ & $\begin{array}{c}0.00006 \\
(0.73)\end{array}$ & $\begin{array}{c}0.00019 \\
(3.01)\end{array}$ \\
\hline $\operatorname{RDIST}_{\mathrm{i}}^{(\mathrm{n})}$ & $\begin{array}{c}-0.00016 \\
(-1.35)\end{array}$ & $\begin{array}{c}-0.00021 \\
(-1.78)\end{array}$ & $\begin{array}{c}-0.00028 \\
(1.99)\end{array}$ & $\begin{array}{c}-0.00010 \\
(-0.76)\end{array}$ & $\begin{array}{c}-0.00020 \\
(-1.10)\end{array}$ \\
\hline UTIL $_{i}^{(n)}$ & & $\begin{array}{c}0.03602 \\
(1.31)\end{array}$ & $\begin{array}{c}0.04072 \\
(1.61)\end{array}$ & $\begin{array}{c}0.07128 \\
(2.51)\end{array}$ & $\begin{array}{c}0.03774 \\
(1.52)\end{array}$ \\
\hline $\operatorname{RUTIL}_{\mathrm{i}}^{(\mathrm{n})}$ & & $\begin{array}{c}-0.12067 \\
(-2.54)\end{array}$ & $\begin{array}{c}-0.03181 \\
(-0.64)\end{array}$ & $\begin{array}{c}-0.13558 \\
(-2.66)\end{array}$ & $\begin{array}{c}-0.04310 \\
(-0.58)\end{array}$ \\
\hline FRINGE $_{i}^{(n)}$ & & $\begin{array}{c}0.04794 \\
(3.85)\end{array}$ & $\begin{array}{c}0.03727 \\
(4.56)\end{array}$ & & $\begin{array}{c}0.03700 \\
(3.14)\end{array}$ \\
\hline $\begin{array}{c}\text { Number of } \\
\text { Bidders }\end{array}$ & & $\begin{array}{c}-0.01191 \\
(-6.99)\end{array}$ & & $\begin{array}{c}-0.01274 \\
(5.47)\end{array}$ & \\
\hline Constant & $\begin{array}{l}1.03793 \\
(111.47)\end{array}$ & $\begin{array}{c}1.07645 \\
(70.93)\end{array}$ & $\begin{array}{c}1.01332 \\
(94.20)\end{array}$ & $\begin{array}{l}1.11427 \\
(63.11)\end{array}$ & $\begin{array}{c}1.01947 \\
(68.23)\end{array}$ \\
\hline Fixed/Random Effects & No & No & Project FE & Firm FE & Project RE \\
\hline $\mathrm{R}^{2}$ & 0.0044 & 0.0218 & 0.5325 & 0.1981 & 0.0071 \\
\hline Number of Obs. & 1938 & 1938 & 1938 & 1938 & 1938 \\
\hline
\end{tabular}

The dependent variable is the total bid divided by the engineer's estimate, where the total bid is the dot product of the estimated quantities and unit prices. Robust standard errors are used to compute t-Statistics, shown in parentheses. 
Table 11: Bid Function Regressions Using Actual Quantities Instead of Estimates

\begin{tabular}{|c|c|c|c|c|c|c|}
\hline Variable & I. & II. & $\overline{~ I I I . ~}$ & IV. & $\overline{\mathrm{V}}$. & VI. \\
\hline $\operatorname{DIST}_{i}^{(\mathrm{n})}$ & $\begin{array}{r}0.00020 \\
(1.52)\end{array}$ & $\begin{array}{r}0.00015 \\
(3.00)\end{array}$ & $\begin{array}{r}0.00021 \\
(1.67)\end{array}$ & $\begin{array}{r}0.00013 \\
(1.11)\end{array}$ & $\begin{array}{r}0.00019 \\
(4.19)\end{array}$ & $\begin{array}{r}0.00019 \\
(4.19)\end{array}$ \\
\hline $\operatorname{RDIST}_{\mathrm{i}}^{(\mathrm{n})}$ & $\begin{array}{r}0.00063 \\
(2.27)\end{array}$ & $\begin{array}{r}-0.00038 \\
(-2.45)\end{array}$ & & & & \\
\hline $\mathrm{UTIL}_{\mathrm{i}}{ }^{(\mathrm{n})}$ & $\begin{array}{r}-0.00587 \\
(-0.11)\end{array}$ & $\begin{array}{r}0.03618 \\
(1.99)\end{array}$ & & & & \\
\hline $\operatorname{RUTIL}_{\mathrm{i}}^{(\mathrm{n})}$ & $\begin{array}{r}0.08879 \\
(0.69)\end{array}$ & $\begin{array}{r}-0.04584 \\
(-0.82)\end{array}$ & & & & \\
\hline FRINGE $_{\mathrm{i}}$ & $\begin{array}{r}-0.00466 \\
(-0.19)\end{array}$ & $\begin{array}{r}0.03100 \\
(3.93)\end{array}$ & $\begin{array}{r}-0.04448 \\
(-1.98)\end{array}$ & $\begin{array}{r}-0.03400 \\
(-1.54)\end{array}$ & $\begin{array}{r}0.02657 \\
(3.43)\end{array}$ & $\begin{array}{r}0.02657 \\
(3.43)\end{array}$ \\
\hline $\begin{array}{c}\text { Number of } \\
\text { Bidders }\end{array}$ & $\begin{array}{r}-0.03031 \\
(-7.67)\end{array}$ & & & & & \\
\hline $\operatorname{NPosAdj}^{(\mathrm{n})}$ & & & $\begin{array}{r}1.57042 \\
(6.41)\end{array}$ & $\begin{array}{r}1.78402 \\
(7.93)\end{array}$ & $\begin{array}{r}1.63960 \\
(6.61)\end{array}$ & $\begin{array}{r}1.84451 \\
(8.13)\end{array}$ \\
\hline $\operatorname{NNegAdj}^{(\mathrm{n})}$ & & & $\begin{array}{r}-3.71090 \\
(-7.78)\end{array}$ & $\begin{array}{r}-3.76479 \\
(-7.74)\end{array}$ & $\begin{array}{r}-3.74572 \\
(-7.80)\end{array}$ & $\begin{array}{r}-3.79619 \\
(-7.70)\end{array}$ \\
\hline $\mathrm{NEX}^{(\mathrm{n})}$ & & & $\begin{array}{r}0.95659 \\
(6.12)\end{array}$ & $\begin{array}{r}1.19168 \\
(9.64)\end{array}$ & $\begin{array}{r}0.96056 \\
(6.11)\end{array}$ & $\begin{array}{r}1.19864 \\
(9.67)\end{array}$ \\
\hline $\operatorname{NDED}^{(\mathrm{n})}$ & & & $\begin{array}{r}-7.35854 \\
(-9.11)\end{array}$ & $\begin{array}{r}-7.35471 \\
(-9.00)\end{array}$ & $\begin{array}{r}-7.38579 \\
(-9.16)\end{array}$ & $\begin{array}{r}-7.36282 \\
(-9.03)\end{array}$ \\
\hline $\mathrm{PCT}^{(\mathrm{n})}$ & & & $\begin{array}{r}0.12582 \\
(3.44)\end{array}$ & & $\begin{array}{r}0.12563 \\
(3.40)\end{array}$ & \\
\hline NOverrun $^{(\mathrm{n})}$ & & & & $\begin{array}{r}0.90527 \\
(15.58)\end{array}$ & & $\begin{array}{r}0.91179 \\
(15.83)\end{array}$ \\
\hline Constant & $\begin{array}{l}1.14662 \\
(36.51)\end{array}$ & $\begin{array}{l}0.97583 \\
(107.06)\end{array}$ & $\begin{array}{r}0.89163 \\
(39.09)\end{array}$ & $\begin{array}{r}0.89748 \\
(40.52)\end{array}$ & $\begin{array}{r}0.96899 \\
(160.46)\end{array}$ & $\begin{array}{c}0.96899 \\
(160.46)\end{array}$ \\
\hline $\begin{array}{l}\text { Fixed } \\
\text { Effects }\end{array}$ & No & Project FE & No & No & Project FE & Project FE \\
\hline $\mathrm{R}^{2}$ & 0.0387 & 0.9324 & 0.0935 & 0.1357 & 0.9134 & 0.9134 \\
\hline Num. of Obs. & 1938 & 1938 & 1938 & 1938 & 1938 & 1938 \\
\hline
\end{tabular}

The dependent variable is the vector product of the unit price bids and the actual quantities, divided by the project estimate. Robust standard errors are used to compute t-Statistics, shown in parentheses. NOverrun ${ }^{(\mathrm{n})}$ is a measure of the quantity-related overrun on standard contract items (those that have a CCDB unit price estimate). This overrun is calculated as the vector product of the CCDB prices (where available) and the difference between actual and estimated quantities. In the final two columns, the coefficients on $\operatorname{NDED}^{(\mathrm{n})}, \mathrm{NEX}^{(\mathrm{n})}, \mathrm{NPosAdj}^{(\mathrm{n})}, \mathrm{NNegAdj}^{(\mathrm{n})}$, $\mathrm{PCT}^{(\mathrm{n})}$, and NOverrun ${ }^{(\mathrm{n})}$ are found by regressing the fixed effects onto these variables (which are constant within a project).

The estimation was also performed using project random effects, but there was little difference in the estimates. Those results are not reported here.

Table 12: Skewed Bidding Regressions

\begin{tabular}{cccc}
\hline \hline Variable & OLS & $\begin{array}{c}\text { Item Code } \\
\text { Fixed Effects }\end{array}$ & $\begin{array}{c}\text { Item Code } \\
\text { Random Effects }\end{array}$ \\
\hline $\begin{array}{c}\text { Percent unit overrun } \\
\text { Constant }\end{array}$ & $0.0265(3.79)$ & $0.0293(5.52)$ & $0.0265(5.37)$ \\
$\mathrm{R}^{2}$ & $0.9994(161.17)$ & $0.9993(157.10)$ & $0.9994(160.14)$ \\
Number of Obs. & 65058 & & 0.0007 \\
\hline
\end{tabular}

The dependent variable is the unit price bid on each contract item, normalized by the average unit bid. The percent unit overrun is the percent difference between the actual and estimated quantities reported for that item. 
Table 13: Structural Estimation

\begin{tabular}{|c|c|c|c|c|}
\hline \multirow{2}{*}{\multicolumn{5}{|c|}{ Parameter Estimates }} \\
\hline & & & & \\
\hline PosAdj $^{(\mathrm{n})} \quad\left(1-\beta_{+}\right)$ & -2.8790 & $\begin{array}{r}-1.6602 \\
(0.4941)\end{array}$ & -3.9141 & $\begin{array}{r}-1.7213 \\
(0.4897)\end{array}$ \\
\hline $\operatorname{NegAdj}^{(\mathrm{n})} \quad\left(1+\beta_{-}\right)$ & 3.2433 & $\begin{array}{r}13.0712 \\
(3.5828)\end{array}$ & 3.9582 & $\begin{array}{r}13.3799 \\
(3.3294)\end{array}$ \\
\hline $\mathrm{EX}^{(\mathrm{n})}$ & -0.1925 & $\begin{array}{r}-1.5216 \\
(0.4077)\end{array}$ & -0.2695 & $\begin{array}{l}-1.8811 \\
(0.3967)\end{array}$ \\
\hline $\operatorname{DED}^{(\mathrm{n})}$ & 11.1010 & $\begin{array}{r}9.7111 \\
(3.6664)\end{array}$ & 11.9661 & $\begin{array}{r}9.6129 \\
(3.3389)\end{array}$ \\
\hline
\end{tabular}

\begin{tabular}{|c|c|c|c|c|}
\hline \multicolumn{5}{|l|}{ Skewing Parameter } \\
\hline$A$ & $-4.1617 \mathrm{E}-06$ & $\begin{array}{r}-2.2535 \mathrm{E}-06 \\
(8.01 \mathrm{E}-07)\end{array}$ & $-5.6233 \mathrm{E}-06$ & $\begin{array}{r}-2.3492 \mathrm{E}-06 \\
(8.57 \mathrm{E}-07)\end{array}$ \\
\hline \multicolumn{5}{|c|}{ Implied Marginal Transaction Costs } \\
\hline Positive Adj. & 3.8790 & $\begin{array}{r}2.6602 \\
{[1.6917,3.6287]}\end{array}$ & 4.9141 & $\begin{array}{r}2.7213 \\
{[1.7615,3.6811]}\end{array}$ \\
\hline Negative Adj. & 2.2433 & $\begin{array}{r}12.0712 \\
{[5.0489,19.0935]}\end{array}$ & 2.9582 & $\begin{array}{r}12.3799 \\
{[5.8542,18.9056]}\end{array}$ \\
\hline Extra Work ** & 1.1925 & $\begin{array}{r}2.5216 \\
{[1.7224,3.3208]}\end{array}$ & 1.2695 & $\begin{array}{r}2.8811 \\
{[2.1036,3.6586]}\end{array}$ \\
\hline Deductions & 10.101 & $\begin{array}{r}8.7111 \\
{[1.5249,15.8973]}\end{array}$ & 10.9661 & $\begin{array}{r}8.6129 \\
{[2.0687,15.1571]}\end{array}$ \\
\hline $\begin{array}{l}\text { Number of Obs } \\
\text { Instruments Used in } \\
\text { Second Stage GMM }\end{array}$ & $\begin{array}{c}1938 \\
\text { Resident Engineer }\end{array}$ & $\begin{array}{c}1938 \\
\text { Resident Engineer }\end{array}$ & $\begin{array}{c}1938 \\
\text { Resident Engineer, } \\
\text { Engineer's Estimate }\end{array}$ & $\begin{array}{c}1938 \\
\text { Resident Engineer, } \\
\text { Engineer's Estimate }\end{array}$ \\
\hline
\end{tabular}

** These estimates represent an upper bound on transaction costs associated with changes in scope. They do not account for marginal costs associated with performing the extra work, which for a reasonable profit margin of 20 percent would lower our estimate by $\$ 0.80$.

Consistent GMM estimates were computed using the identity matrix as the weighting matrix. In a second step, efficient GMM estimates were computed using the optimal weighting matrix derived from the variance of the sample moments in the first step. Standard errors were computed for the efficient estimator, and they appear in parentheses. These were also used to derive 95\% confidence intervals (in brackets) for the implied transaction costs. 
Table 14a: Markup Decomposition (All Bidders)

\begin{tabular}{|c|c|c|c|c|c|c|c|c|}
\hline Percentile & $\begin{array}{l}\text { Direct } \\
\text { Markup } \\
\left(b_{i}-c_{i}\right) q^{a}\end{array}$ & $\begin{array}{c}\text { Direct } \\
\text { Markup } \\
\text { Estimate }\end{array}$ & $\begin{array}{c}\text { Ex-Post } \\
\text { Changes } \\
\begin{array}{c}A+X+D- \\
T C\left(A_{+}, A_{-},\right. \\
X, D)\end{array}\end{array}$ & $\begin{array}{l}\text { Ex-Post } \\
\text { Changes } \\
\text { Estimate }\end{array}$ & $\begin{array}{c}\text { Skewing } \\
\text { Penalty } \\
\alpha \cdot \\
\sum_{t}\left[\left(b_{i}-b\right)^{2}\right. \\
\left.\mid \% \text { over }_{t} \mid\right]\end{array}$ & $\begin{array}{l}\text { Skewing } \\
\text { Penalty } \\
\text { Estimate }\end{array}$ & $\begin{array}{c}\text { Total } \\
\text { Profit } \\
\quad \pi\end{array}$ & $\begin{array}{c}\text { Total } \\
\text { Profit } \\
\text { Estimate }\end{array}$ \\
\hline 10 & 26,080 & $5.8 \%$ & $-1,250,830$ & $-40.6 \%$ & -135.16 & $-0.0088 \%$ & 6,176 & $1.3 \%$ \\
\hline 20 & 54,117 & $9.1 \%$ & $-647,812$ & $-28.1 \%$ & -18.63 & $-0.0012 \%$ & 11,392 & $1.8 \%$ \\
\hline 30 & 101,028 & $11.9 \%$ & $-383,068$ & $-20.7 \%$ & -6.24 & $-0.0003 \%$ & 18,966 & $2.2 \%$ \\
\hline 40 & 175,646 & $14.1 \%$ & $-230,172$ & $-16.4 \%$ & -1.89 & $-0.0001 \%$ & 31,073 & $2.8 \%$ \\
\hline 50 & 254,311 & $18.1 \%$ & $-178,137$ & $-11.4 \%$ & -0.60 & $0.0000 \%$ & 52,127 & $3.6 \%$ \\
\hline 60 & 374,272 & $22.9 \%$ & $-105,839$ & $-9.6 \%$ & -0.21 & $0.0000 \%$ & 82,845 & $4.6 \%$ \\
\hline 70 & 556,655 & $28.5 \%$ & $-55,993$ & $-7.4 \%$ & -0.08 & $0.0000 \%$ & 131,306 & $6.0 \%$ \\
\hline 80 & 961,665 & $38.1 \%$ & $-28,053$ & $-4.6 \%$ & -0.02 & $0.0000 \%$ & 227,667 & $8.7 \%$ \\
\hline 90 & $1,870,754$ & $55.8 \%$ & $-11,860$ & $-2.2 \%$ & 0.00 & $0.0000 \%$ & 487,750 & $16.2 \%$ \\
\hline
\end{tabular}

Table 14b: Ex-Post Profit Decomposition (All Winning Bidders)

\begin{tabular}{|c|c|c|c|c|c|c|c|c|}
\hline Percentile & $\begin{array}{c}\text { Direct } \\
\text { Markup } \\
\left(b_{i}-c_{i}\right) q^{a}\end{array}$ & $\begin{array}{c}\text { Direct } \\
\text { Markup } \\
\text { Estimate }\end{array}$ & $\begin{array}{c}\text { Ex-Post } \\
\text { Changes } \\
\\
A+X+D- \\
T C\left(A_{+}, A_{-},\right. \\
X, D)\end{array}$ & $\begin{array}{l}\text { Ex-Post } \\
\text { Changes } \\
\text { Estimate }\end{array}$ & $\begin{array}{c}\text { Skewing } \\
\text { Penalty } \\
\\
\alpha \cdot \\
\sum_{t}\left[\left(b_{i}-b\right)^{2}\right. \\
\mid \% \text { Over } t \mid]\end{array}$ & $\begin{array}{l}\text { Skewing } \\
\text { Penalty } \\
\text { Estimate }\end{array}$ & $\begin{array}{c}\text { Total } \\
\text { Profit } \\
\pi\end{array}$ & $\begin{array}{c}\text { Total } \\
\text { Profit } \\
\text { Estimate }\end{array}$ \\
\hline 10 & 58,668 & $12.1 \%$ & $-1,356,185$ & $-41.5 \%$ & -128.89 & $-0.0068 \%$ & 32,351 & $5.4 \%$ \\
\hline 20 & 126,980 & $15.7 \%$ & $-771,265$ & $-29.3 \%$ & -14.43 & $-0.0007 \%$ & 61,427 & $6.4 \%$ \\
\hline 30 & 230,937 & $18.6 \%$ & $-486,765$ & $-21.7 \%$ & -4.98 & $-0.0002 \%$ & 102,013 & $7.8 \%$ \\
\hline 40 & 338,568 & $23.6 \%$ & $-284,847$ & $-16.7 \%$ & -1.47 & $-0.0001 \%$ & 154,834 & $9.8 \%$ \\
\hline 50 & 491,083 & $29.2 \%$ & $-193,573$ & $-11.6 \%$ & -0.59 & $0.0000 \%$ & 225,931 & $11.9 \%$ \\
\hline 60 & 682,536 & $35.6 \%$ & $-132,528$ & $-9.6 \%$ & -0.20 & $0.0000 \%$ & 295,515 & $14.8 \%$ \\
\hline 70 & $1,032,579$ & $42.8 \%$ & $-68,173$ & $-7.2 \%$ & -0.09 & $0.0000 \%$ & 425,906 & $20.4 \%$ \\
\hline 80 & $1,462,602$ & $56.2 \%$ & $-30,032$ & $-4.6 \%$ & -0.03 & $0.0000 \%$ & 711,475 & $27.1 \%$ \\
\hline 90 & $2,838,608$ & $89.9 \%$ & $-13,920$ & $-2.4 \%$ & -0.01 & $0.0000 \%$ & $1,259,569$ & $50.7 \%$ \\
\hline
\end{tabular}

Table 15: Markups Implied by Standard Model

Without Transaction Costs or Ex-Post Changes

\begin{tabular}{c|rr|rr}
\hline \hline \multirow{2}{*}{ Percentile } & \multicolumn{2}{|c|}{ All Bidders } & \multicolumn{2}{c}{ Winning Bidders Only } \\
\cline { 2 - 5 } & $\begin{array}{c}\text { Direct } \\
\text { Markup } \\
\left(b_{i}-c_{i}\right) q^{a}\end{array}$ & $\begin{array}{c}\text { Direct } \\
\text { Markup } \\
\text { Estimate }\end{array}$ & $\begin{array}{c}\text { Direct } \\
\text { Markup } \\
\left(b_{i}-c_{i}\right) q^{a}\end{array}$ & $\begin{array}{c}\text { Direct } \\
\text { Markup }\end{array}$ \\
\hline 10 & 6,001 & $1.3 \%$ & 35,121 & Estimate \\
20 & 11,547 & $1.8 \%$ & 62,601 & $6.4 \%$ \\
30 & 19,067 & $2.2 \%$ & 103,610 & $8.1 \%$ \\
40 & 30,829 & $2.8 \%$ & 153,438 & $9.9 \%$ \\
50 & 51,167 & $3.6 \%$ & 224,788 & $12.1 \%$ \\
60 & 82,976 & $4.4 \%$ & 298,660 & $15.3 \%$ \\
70 & 132,191 & $5.9 \%$ & 419,576 & $19.7 \%$ \\
80 & 224,722 & $8.8 \%$ & 672,689 & $27.2 \%$ \\
90 & 464,602 & $15.8 \%$ & $1,143,994$ & $50.7 \%$ \\
\hline
\end{tabular}


Table 16: Transaction Costs Lower Bound

\begin{tabular}{|c|c|c|c|}
\hline Percentile & Total Transaction Costs & $\begin{array}{l}\text { As a Fraction of } \\
\text { the Estimate }\end{array}$ & $\begin{array}{c}\text { As a Fraction of } \\
\text { the Estimated Ex-Post Profit }\end{array}$ \\
\hline 10 & 13,952 & $2.5 \%$ & $12.2 \%$ \\
\hline & {$[6,624,21,280]$} & {$[1.1 \%, 4.0 \%]$} & {$[6.0 \%, 18.3 \%]$} \\
\hline 20 & 32,011 & $5.3 \%$ & $28.2 \%$ \\
\hline & {$[16,076,47,945]$} & {$[2.5 \%, 8.0 \%]$} & {$[16.0 \%, 40.5 \%]$} \\
\hline 30 & 74,297 & $8.1 \%$ & $45.8 \%$ \\
\hline 40 & $\begin{array}{c}{[46,029,102,564]} \\
142,054\end{array}$ & $\begin{array}{c}{[3.8 \%, 12.3 \%} \\
10.6 \%\end{array}$ & $\begin{array}{c}{[24.5 \%, 67.1 \%]} \\
69.4 \%\end{array}$ \\
\hline & {$[54,049,230,060]$} & {$[4.5 \%, 16.8 \%]$} & {$[34.1 \%, 104.7 \%]$} \\
\hline 50 & $\begin{array}{c}215,862 \\
{[118,958, \quad 312,767]}\end{array}$ & $\begin{array}{c}14.6 \% \\
{[8.3 \%, \quad 20.9 \%]}\end{array}$ & $\begin{array}{c}102.2 \% \\
{[48.5 \%, \quad 155.8 \%]}\end{array}$ \\
\hline 60 & $\begin{array}{c}348,860 \\
{[211,132, \quad 486,588]}\end{array}$ & $\begin{array}{c}18.7 \% \\
{[10.4 \%, \quad 26.9 \%]}\end{array}$ & $\begin{array}{c}144.0 \% \\
{[74.2 \%, \quad 213.9 \%]}\end{array}$ \\
\hline 70 & $\begin{array}{c}589,379 \\
{[251,585,927,174]}\end{array}$ & $\begin{array}{c}25.3 \% \\
{[14.2 \%, \quad 36.4 \%]}\end{array}$ & $\begin{array}{c}211.3 \% \\
{[119.6 \%, \quad 303.1 \%]}\end{array}$ \\
\hline 80 & $\begin{array}{c}919,457 \\
{[440,170, \quad 1,398,744]}\end{array}$ & $\begin{array}{c}33.0 \% \\
{[16.4 \%, 49.6 \%]}\end{array}$ & $\begin{array}{c}296.7 \% \\
{[140.9 \%, 452.5 \%]}\end{array}$ \\
\hline 90 & $\begin{array}{c}1,597,358 \\
{[810,019,2,384,696]}\end{array}$ & $\begin{array}{c}46.5 \% \\
{[29.0 \%, 64.0 \%]}\end{array}$ & $\begin{array}{c}454.1 \% \\
{[230.3 \%, 677.9 \%]}\end{array}$ \\
\hline \multicolumn{4}{|c|}{ Upper Bound } \\
\hline Percentile & Total Transaction Costs & $\begin{array}{l}\text { As a Fraction of } \\
\text { the Estimate }\end{array}$ & $\begin{array}{c}\text { As a Fraction of } \\
\text { the Estimated Ex-Post Profit }\end{array}$ \\
\hline 10 & $\begin{array}{c}21,231 \\
{[3,716, \quad 38,745]}\end{array}$ & $\begin{array}{c}3.8 \% \\
{[2.6 \%, \quad 5.1 \%]}\end{array}$ & $\begin{array}{c}18.8 \% \\
{[12.8 \%, 24.7 \%]}\end{array}$ \\
\hline 20 & $\begin{array}{c}48,122 \\
{[30,602,65,641]}\end{array}$ & $\begin{array}{c}7.4 \% \\
{[5.1 \%, 9.8 \%]}\end{array}$ & $\begin{array}{c}37.8 \% \\
{[25.8 \%, 49.8 \%]}\end{array}$ \\
\hline 30 & $\begin{array}{c}102,277 \\
{[65,848, \quad 138,706]}\end{array}$ & $\begin{array}{c}10.3 \% \\
{[6.8 \%, \quad 13.7 \%]}\end{array}$ & $\begin{array}{c}66.2 \% \\
{[45.0 \%, 87.3 \%]}\end{array}$ \\
\hline 40 & $\begin{array}{c}184,458 \\
{[123,341, \quad 245,575]}\end{array}$ & $\begin{array}{c}13.7 \% \\
{[9.3 \%, \quad 18.0 \%]}\end{array}$ & $\begin{array}{c}92.1 \% \\
{[47.8 \%, \quad 136.4 \%]}\end{array}$ \\
\hline 50 & $\begin{array}{c}303,980 \\
{[189,191,418,768]}\end{array}$ & $\begin{array}{c}18.1 \% \\
{[12.4 \%, 23.9 \%]}\end{array}$ & $\begin{array}{c}138.5 \% \\
{[73.6 \%, 203.4 \%]}\end{array}$ \\
\hline 60 & $\begin{array}{c}435,993 \\
{[297,375,574,612]}\end{array}$ & $\begin{array}{c}24.9 \% \\
{[16.2 \%, \quad 33.5 \%]}\end{array}$ & $\begin{array}{c}184.0 \% \\
{[122.2 \%, \quad 245.9 \%]}\end{array}$ \\
\hline 70 & $\begin{array}{c}676,961 \\
{[436,210,917,711]}\end{array}$ & $\begin{array}{c}32.5 \% \\
{[14.9 \%, 50.0 \%]}\end{array}$ & $\begin{array}{c}266.4 \% \\
{[171.6 \%, 361.1 \%]}\end{array}$ \\
\hline 80 & $\begin{array}{c}1,165,243 \\
{[731,545, \quad 1,598,940]}\end{array}$ & $\begin{array}{c}42.4 \% \\
{[27.1 \%, \quad 57.6 \%]}\end{array}$ & $\begin{array}{c}387.3 \% \\
{[256.8 \%, 517.8 \%]}\end{array}$ \\
\hline 90 & $\begin{array}{c}2,024,909 \\
{[1,321,579, \quad 2,728,239]}\end{array}$ & $\begin{array}{c}59.6 \% \\
{[38.2 \%, 81.1 \%]}\end{array}$ & $\begin{array}{c}587.0 \% \\
{[123.6 \%, \quad 1050.4 \%]}\end{array}$ \\
\hline
\end{tabular}

The transaction cost is calculated as $2.6602\left(A_{+}\right)+12.0712\left|A_{-}\right|+1.5216(X)+8.7111|D|$. We consider this to be a lower bound because it attributes much of the coefficient on extra work to marginal costs of production, rather than pure transaction costs. This amounts to an assumption that firms perform extra work at a zero percent profit margin. Each dollar awarded through a change in scope just covers the cost of performing that work. With $\$ 1$ of marginal costs for every $\$ 1$ of extra work, that leaves approximately $\$ 1.52$ to be explained by transaction costs. The other extreme would be to assume a $100 \%$ profit margin on extra work, making it analogous to positive adjustments in compensation. This upper bound is calculated as $2.6602\left(A_{+}\right)+12.0712\left|A_{-}\right|+2.5216(X)+8.7111|D| .95 \%$ confidence intervals, appearing in brackets, were calculated by taking the lower and upper confidence bounds of the parameter estimates and using them in the transaction cost equation instead of the point estimates. 